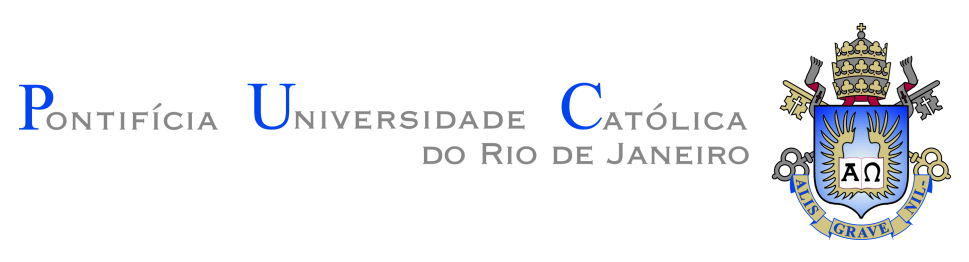

Daniel Malvezzi Doine

Foreign Exchange Interventions and Covered Interest Parity Deviations

Dissertação de Mestrado

Dissertation presented to the Programa de Pós-graduação em Economia da PUC-Rio in partial fulfillment of the requirements for the degree of Mestre em Economia .

Advisor: Prof. Márcio Gomes Pinto Garcia 


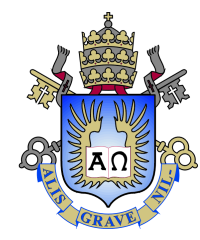

Daniel Malvezzi Doine

\section{Foreign Exchange Interventions and Covered Interest Parity Deviations}

Dissertation presented to the Programa de Pós-graduação em Economia da PUC-Rio in partial fulfillment of the requirements for the degree of Mestre em Economia. Approved by the Examination Committee.

Prof. Márcio Gomes Pinto Garcia

Advisor

Departamento de Economia - PUC-Rio

Prof. Marcelo Cunha Medeiros

Departamento de Economia - PUC-Rio

Marcos de Carvalho Chamon

Research Department - International Monetary Fund 
All rights reserved.

\section{Daniel Malvezzi Doine}

B.A., Economics, Universidade de São Paulo, 2016

Bibliographic data

Doine, Daniel Malvezzi

Foreign Exchange Interventions and Covered Interest $\mathrm{Pa}$ rity Deviations / Daniel Malvezzi Doine; advisor: Márcio Gomes Pinto Garcia. - Rio de janeiro: PUC-Rio , Departamento de Economia, 2020.

v., 55 f: il. color. ; $30 \mathrm{~cm}$

Dissertação (mestrado) - Pontifícia Universidade Católica do Rio de Janeiro, Departamento de Economia.

Inclui bibliografia

1. Economia - Teses. 2. Economia - Teses. 3. Intervenções cambiais;. 4. Paridade coberta da taxa de juros;. 5. Artificial Counterfactual;. 6. Local Projection;. 7. Taxa de câmbio;. 8. Taxa de câmbio futura;. 9. Derivativos;. I. Garcia, Márcio Gomes Pinto. II. Pontifícia Universidade Católica do Rio de Janeiro. Departamento de Economia. III. Título. 


\section{Acknowledgments}

Several people are involved in the process of elaborating on this thesis, and each one has a unique contribution.

First of all, I would like to thanks my advisor Prof. Márcio Garcia, for the excellent guidance, friendship, and advice, which were very important in my formation.

I also thank Prof. Marcelo Medeiros and Marcos Chamon for important comments, suggestions, and insights.

During my time at PUC, I appreciated the classes of the professors Marcelo Medeiros, Fábio Miessi, Ruy Ribeiro, Eduardo Zilberman, and Marcelo de Paiva Abreu. It was a privilege to spend some time listening and absorbing part of your knowledge.

This project would not be possible without the support of my family, my parents Mauro and Rita, my sister Sofia, and my grandparents, Mauro and Maria.

Finally, I am very grateful to all my friends and my classmates. My period in Rio would not be the same without your friendship.

This study was partially financed by the Coordenação de Aperfeiçoamento Pessoal de Nível Superior - Brasil (CAPES) - Código de Financiamento 001. I also thanks the $\mathrm{CNPq}$ for the financial support. 


\section{Abstract}

Doine, Daniel Malvezzi; Garcia, Márcio Gomes Pinto (Advisor). Foreign Exchange Interventions and Covered Interest Parity Deviations. Rio de Janeiro, 2020. 55p. Dissertação de mestrado - Departamento de Economia, Pontifícia Universidade Católica do Rio de Janeiro.

Traditionally, much has been written about the effects of FX (foreign exchange) sterilized interventions on exchange rates, both theoretically and empirically, with mixed results. More recently, the international finance literature has tried to explain the deviations from the well-known Covered Interest Parity (CIP) condition that have, since the 2008 Great Financial Crisis, arisen among advanced economies currencies. Here, we originally merge these two strands of the literature by analyzing the effects of sterilized FX interventions on the CIP (Covered Interest Parity) deviation. Our sample is composed of Brazilian Central Bank FX interventions between 2009 and 2020. This period contains a major program of announced FX interventions in response to the Taper Tantrum, in 2013, which has already been shown to have significantly affected the level of the exchange rate (Chamon, Garcia, and Souza (2017)). To gauge the effects, we build a counterfactual employing the ArCo methodology, developed by Carvalho, Masini, and Medeiros (2018), and also make use of Jordà (2005) Local Projections. The results indicate that selling US dollars in the futures market increases CIP deviations while buying US dollar futures has the opposite effect. Offering US dollar repo credit lines points to a short-lived decrease in the deviation. The number of sterilized sales or purchases of spot currency seems not to be high enough to lead to conclusive results.

\section{Keywords}

Foreign exchange intervention; Covered interest parity; Artificial Counterfactual; Local Projection; Exchange rate; Forward exchange rate; Derivatives; 


\section{Resumo}

Doine, Daniel Malvezzi; Garcia, Márcio Gomes Pinto. Intervenções Cambiais e Desvios na Paridade Coberta da Taxa de Juros. Rio de Janeiro, 2020. 55p. Dissertação de Mestrado - Departamento de Economia, Pontifícia Universidade Católica do Rio de Janeiro.

Tradicionalmente, muitos trabalhos têm estudado os efeitos das intervenções cambiais esterilizadas nas taxas de câmbio, tanto empiricamente quanto teoricamente, encontrando resultados mistos. Mais recentemente, a literatura de finanças internacionais têm procurado explicar os desvios na Paridade Coberta da Taxa de Juros (PCJ), que vem sendo observado entre as moedas das economias desenvolvidas após a Grande Crise Financeira de 2008. Neste trabalho, ligamos as duas literaturas ao estudar o efeito das intervenções cambiais nos desvios na paridade coberta de juros. Nossa amostra consiste nas intervenções realizadas pelo Banco Central do Brasil entre os anos de 2009 e 2020. Este período contempla o programa de intervenções pré-anunciadas de 2013, implementado no contexto do Taper Tantrum, e que já mostrou ter afetado significantemente as taxas de câmbio (Chamon, Garcia e Souza (2017)). Para avaliar os efeitos, construímos uma série contrafactual utilizando a metodologia ArCo, desenvolvida por Carvalho, Masini e Medeiros (2018), e também estimando funções impulso resposta utilizando Local Projection, desenvolvida por Jordà (2005). Os resultados indicam que a venda de dólares no mercado futuro aumentam os desvios na PCJ, enquanto que compras de dólares tem o efeito oposto. A oferta de dólares via contratos de recompra diminui os desvios no curto prazo. As intervenções no mercado a vista apresentam resultados inconclusivos.

\section{Palavras-chave}

Intervenções cambiais; Paridade coberta da taxa de juros; Artificial Counterfactual; Local Projection; Taxa de câmbio; Taxa de câmbio futura; Derivativos; 


\section{Table of contents}

1 Introduction $\quad 10$

$\begin{array}{lll}\text { 1.0.1 Related Literature } & 14\end{array}$

2 Methodology $\quad 17$

$\begin{array}{ll}\text { 2.0.1 Artificial Counterfactual (ArCo) } & 17\end{array}$

$\begin{array}{ll}2.0 .1 .1 & 19\end{array}$

$\begin{array}{ll}2.0 .2 \text { Local Projection } & 20\end{array}$

3 Data $\quad 23$

3.0.1 The Program of Daily FX Intervention 23

$\begin{array}{ll}3.0 .2 & \text { CIP Deviations } \\ 3.0 .2 .1 & 25\end{array}$

3.0.2.1 Brazil 26

$\begin{array}{ll}3.0 .3 & \text { Interventions }\end{array}$

4 Results $\quad 30$

4.0.1 Daily ArCo 31

4.0.2 Weekly ArCo 34

4.0.3 Local Projections 36

5 Conclusion $\quad 41$

$\begin{array}{lll}\text { A Data Appendix } & 45\end{array}$

B Results Appendix $\quad 46$ 


\section{List of figures}

Figure 1.1 CIP Deviation and Swap Interventions 13

$\begin{array}{lll}\text { Figure 3.1 Periods of Analysis } & 25\end{array}$

$\begin{array}{lll}\text { Figure } 3.2 & \text { Foreign Exchange Interventions } & 28\end{array}$

Figure 4.1 Average Maturity of the New Offered Swap Contracts 32

Figure 4.2 Results - Daily ArCo 33

Figure 4.3 Results - Weekly ArCo 35

Figure 4.4 Swap Interventions Effect on CIP Deviations 36

Figure 4.5 Swap Interventions Effect on CIP Deviations - Covid-19 37

Figure 4.6 Spot Interventions Effect on CIP Deviations 38

Figure 4.7 Reverse Swap Effect on CIP Deviations - 2H2019 39

Figure 4.8 Repo Interventions Effect on CIP Deviations 39

Figure B.1 Results - Daily ArCo - Pre 1 48

Figure B.2 Results - Daily ArCo - Pre 2 49

Figure B.3 Results - Weekly ArCo - Pre 1 50

Figure B.4 Results - Weekly ArCo - Pre 2

Figure B.5 Results - Adjusted R-Squared $\quad 52$

Figure B.6 Swap Interventions Effect on CIP Deviations 53

Figure B.7 Swap Interventions Effect on CIP Deviations - Covid-19 53

Figure B.8 Spot Interventions Effect on CIP Deviations 54

Figure B.9 Reverse Swap Effect on CIP Deviations - 2H2019 54

Figure B.10 Repo Interventions Effect on CIP Deviations 55 


\section{List of tables}

Table 3.1 CIP Deviations - Descriptive Analyses 27

Table 3.2 Samples - Local Projection (LP) 29

Table B.1 List of the Models - Daily Data 46

Table B.2 List of the Models - Weekly Data 47 


\section{Introduction}

In the onset of unconventional monetary policies ruled by central banks of developed economies in the period that followed the 2008 Global Financial Crisis (GFC), the Emerging Market Economies (EME) were the destiny of a massive flow of capital. This movement leads EME central banks to use foreign exchange interventions (FXI) to accumulate international reserves, in the period of capital inflow, and to smooth the effects of capital outflow on the exchange rates from 2013 on, in the so-called taper tantrum.

These interventions brought out the question of whereas sterilized FXI can or cannot affect the exchange rate path. In the last decade, several papers have addressed this question, for different periods, countries, and using several econometric techniques, always aiming to circumvent the inherent endogeneity problem in this literature, related to the fact that central banks intervene as a response to the exchange rate movements. Answering this question is not a brand new desire in international economics. Sarno and Taylor (2001) surveyed the 1980 and 90's literature. A survey of the recent FXI ruled by the EME can be found in Menkhoff (2013). The results vary from country and period but point to the effectiveness of those interventions.

A second and more recent wave of papers is investigating a slightly different question of to what extent these FXI produce spillovers over other economic variables rather than the exchange rate. Perhaps the first paper to carry out this question was Blanchard et al. (2015), investigating how capital flows are affected by the interventions. Hofmann et al. (2019) and Gonzalez et al. (2019), for instance, analyze the effect on credit market.

Beyond the FXI's, the 2008 GFC also triggered deviations on the Covered Interest Parity (CIP) among the developed economies' currencies. In the scenario of lack of risks, any difference between the forward premium and the interest rate differential, the CIP components, would return a risk-free positive profit, so any deviation is expected to vanish by players operating this wedge. There is flourishing literature investigating the reasons behind the deviations. Although quite common among emerging markets due to the country and convertibility risks, the parity was holding for the G10 currency historically. Among the causes, the most cited one is related to changes in 
banking regulation, diminishing bank's capacity to operate these arbitrage and leading to the deviations. Then, the deviations emerge as a result of a lack of liquidity in the interbank loan market across the countries.

In this paper, we link this two literature and investigate the FXI effects on the CIP deviations. We analyze Brazilian interventions, from 2009 until 2020, including the major program of interventions ruled by the Brazilian Central Bank (BCB) between 2013 and 2015. We employ two different and complementary methodologies to capture the CIP dynamics as a response for an intervention: the Artificial Counterfactual (ArCo), developed by Carvalho et al. (2018), and the Jordà (2005) Local Projection.

To construct the ArCo statistics and evaluate the major swap program effect on the CIP deviation, we build up a control group composed of countries that did not intervene in the FX market between 2013-2015. Besides this very studied program, we also extend our sample from 2009 until 2020 to include spot and repo interventions. The sample also contemplates recent interventions ruled as a response to the Covid-19 crisis. We then use the Local Projections to estimate IRF of CIP deviations responses to interventions shocks. This last methodology allows us to measure the exact impact of a specific intervention, as well as study asymmetries between purchasing or selling foreign currency.

The reason we use two methodologies for the problem regards the nature of interventions. In the major program of 2013-2015, the Central Bank ruled daily pre-announced interventions of an equal amount. Then, any IRF would not capture this constant and continuous shock appropriately, as well as the whole program effect, as the ArCo does. The drawbacks of ArCo include the lack of information about a specific intervention and the difficulty in building a control group. On the other hand, the interventions ruled outside the program consist of unannounced and different-size operations, the reason why we use Local Projection's IRF. Differently from the ArCo, which captures the average sample effect, LP's IRF allows us to understand the daily effect of an intervention. Moreover, expanding the sample period, we can analyze other types of interventions used by the BCB: spot and repurchase (repo) credit lines operations. The main challenge of Local Projection estimations is to define intervals of estimations since spot and forward interventions are clustered in specific periods while repo interventions are less clustered but observed in the whole sample.

The results we found can be divided into three components. First, we find that forward intervention indeed affects CIP deviations, and not only in the short term. A sale of forward currency by a monetary authority puts downward pressure on the forward prices, shrinking the forward premium and 
widening the parity deviations. The ArCo results indicate that the major swap program leads to an increase in the CIP deviations of approximately 35 basis points, on average. Local Projection impulse response functions' indicate that a forward intervention leads to an increase of up to 10 basis points on the CIP deviations, and this effect persists around 20 days. We also find evidence of symmetric effect regarding reverse swap operations.

Second, there is evidence that this effect is not significant when looking at spot market interventions, illustrating a possible difference between these two available instruments on the central bank toolkit. However, we observe this result cautiously since the spot market interventions contemplated in our sample were ruled in specific environments, as explained in Section 3, which can weaken the conclusions. The results for repo interventions sales, on the other hand, indicate a decrease in the deviations, especially on the shorter maturity. We believe this pattern is consistent with BCB strategy adopted on the major swap program, when repo sales were released every week, aiming to give liquidity to the market.

Our findings are robust for several tests. First, using daily data, the ArCo is robust for several specifications and lags used. A weakness of the daily frequency is the lack of data related to capital flows for most countries in the control group. Then, we add to previous analyses weekly data of bonds and equity flows, and results remain the same for the new data frequency. Lastly, we take advantage of a detailed interventions data, released by the Brazilian Central Bank, to estimate Local Projection impulse response functions. The results for the swap goes in the same line of the ArCo results. Local Projection also adds to our study by differentiating long and short intervention's position and operations on the spot and repo markets.

To elucidate the variables we are working, Figure 1.1 shows the 12-month CIP deviation for Brazil and the thirteen countries used as the control group on the ArCo analysis, as will be detailed in Section 2. The period corresponds to the 2013-2015 major pre-announcement FXI program. The grey area, on the right-hand-side, corresponds to the accumulated offered swap amount. Brazil's CIP deviation is highlighted and shows some interesting patterns. The most important is the increase right after the program announcement, pointing to the effect we aim to capture. Second, the Brazilian deviation is higher than its peers, on average, and increases along with the program.

The mechanism we are studying works as follows. Suppose the Brazilian Central Bank offer dollars in the forward market aiming to provide liquidity. The increase in the supply puts downward pressure on the forward exchange rates. Once the spot exchange rate and the foreign interest rate remain 
Figure 1.1: CIP Deviation and Swap Interventions

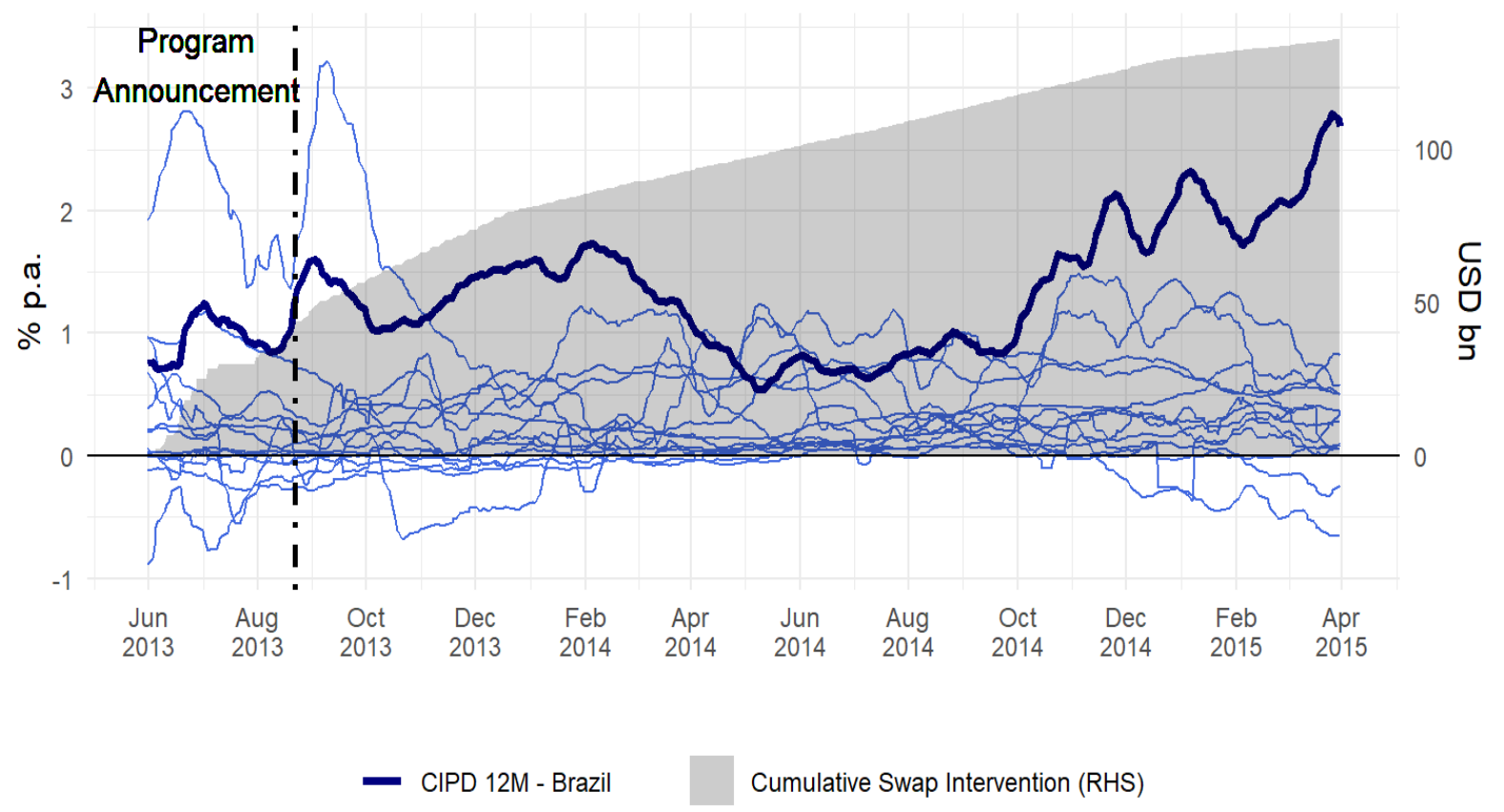

Figure 1.1 shows the 10-day moving average CIP deviations, for the maturity of 12 months. The Brazilian real deviation is highlighted in dark blue. The light blue lines represent deviations of the control group: Australia, Canada, Chile, Czech Rep, Euro, Hungary, India, Israel, Japan, Mexico, Philippines, South Korea, and Turkey. The criteria used to select the control group are explained in Section 2.0.1.1. The program was launched on Aug 22, 2013 , represented by the traced vertical line. On the right-hand side, the area filled in grey represents the cumulative swap interventions, started on May 31, 2013, and lasting until the end of the program, on March 31, 2015.

unchanged, the on-shore dollar rate, known as Cupom Cambial, must increase. As we explain later, in Section 3, the CIP in Brazil can be expressed as the Cupom Cambial less the LIBOR. Then, selling USD on the forward market widens the parity. Through this mechanism, we expect a similar effect on spot market interventions.

We believe our study is relevant in two ways. First, measuring FXI spillovers is a relevant contribution, since FXI is widely and frequently adopted for several countries, especially Brazil. The amount of resources applied in this policy is also relevant. Second, understanding the components behind the CIP deviations is quite relevant since these deviations represent a market failure, which implies inefficiency and loss of welfare [Cerutti et al. (2019)]. In the model developed by Amador et al. (2019), for instance, the CIP deviation is the measure of welfare loss incurred by a central bank that pursues an exchange rate policy. Still, for the special case of Brazil, this deviation represents the cost incurred by the $\mathrm{BCB}$ of carrying forward international reserves.

Our main contribution to the literature is to capture the dynamics of 
this impact. Garcia and Volpon (2014) was the first to document the contemporaneous relationship between forwarding interventions and CIP deviations. Walker (2019) build up a static model showing the asymmetry between the spot and forward prices during the intervention in the forward market. The author also shows contemporaneous evidence for Mexico and Peru. We contribute by bringing new methodologies for this literature, the ArCo and Local Projection, and understanding the long-term impact of such interventions.

The rest of the paper is organized as follows. In the sequence, there is a literature review. In Section 2, we present the ArCo and Local Projection methodology. In Section 3 we present the data and how we construct the CIP. In Section 4 we show the results for both methodologies and in Section 5 we conclude.

\subsection{1 \\ Related Literature}

In the wake of the 2008 GFC, several emerging market economies adopt FXI to shield their currencies against the capital flows caused by the Quantitative Easing (QE), reviving the question of whether are these sterilized interventions effective or not.

Several papers in the last decade have addressed this question. Chamon et al. (2017), which share the ArCo methodology and the major swap intervention program used in the present study, conclude that the swap interventions led to an appreciation of the Brazilian real in 10 percent; Kohlscheen and Andrade (2014) use high-frequency data and also find a significant impact on USDBRL, for the years of 2011 and 2013.

Dominguez (2019), in turn, generalizes the study by looking at several emerging economies, in a larger period. The results are, however, inconclusive, and the effectiveness depends on the period and the country under analysis. A great contribution of Dominguez (2019) regards the methodology of defining FXI, as many central banks do not display these data explicitly. This subject is also explored by Blanchard et al. (2015), using their results to categorize the countries between floaters and de facto interveners.

Nedeljkovic and Saborowski (2019) address a slightly different question regarding the relative effectiveness in intervening on the spot or the forward market. Looking at the Brazil interventions, for the period 2008-2013, the authors find similar effects on the USDBRL path using both instruments. The reason for Nedeljkovic and Saborowski (2019) use Brazil data is because BCB used both instruments simultaneously in that period, although it not include the swap program. Oliveira (2020) reaches the same result, the effectiveness 
of both instruments, employing GMM estimations, using BCB interventions from 2006 until 2016. These findings motivated us to investigate if spot and forward interventions have the same effect on CIP deviation.

A more recent literature study to what extent these FXI produce spillovers on other economic variables. Hofmann et al. (2019) study the effect of FXI on domestic credit in Colombia. Using sectoral microdata, they find that the purchase of dollars dampens the flow of new domestic corporate loans in the country. Gonzalez et al. (2019) shows that FXI accomplished by BCB diminished by half the effects of the GFC on local credit supply and employment.

The papers we follow closer are Walker (2019) and Garcia and Volpon (2014). Investigating the interventions that occurred in 2008-2009 and 20132014, Garcia and Volpon (2014) conclude that domestic non-deliverable forwards (DNDF) interventions provide BCB's an alternative intervention strategy by providing a hedge for the market players. The authors find empirical evidence of a contemporaneous relationship in Cupom Cambial and this kind of intervention. Walker (2019) creates a static model to analyze the differences between both instruments and concludes that, although they have a similar impact on the spot price, their effects are different on the central bank's net forward position. According to the author, "A change in the central bank's forward position has a greater effect on the forward rate than on the spot rate" which, in turn, widens the CIP deviations. It is in this literature where our major contribution, since our paper is the first to capture the dynamic effects of FXI on CIP deviations, up to our knowledge.

Finally, our paper is also related to the CIP deviations studies, the growing literature that tries to understand the phenomenon occurring in the advanced economies after the GFC. The main question to be tackled in these papers is what are the determinants of these deviations? Avdjiev et al. (2019) highlights the role of the strong dollar on the banks' balance sheet, diminishing their appetite for arbitrage possible deviations. Du et al. (2018) deserve a prominent role in financial regulation and how they pressure the banks' balance sheet. In the years that followed the GFC, tighter regulations on the banking system diminished the banks' capacity to arbitrage the deviations. The authors also observed that countries with lower nominal interest rates showed higher deviations from CIP. Cerutti et al. (2019) attribute the deviations not only for regulatory changes, after the GFC, but for multiple macro-financial factors. Beyond the prominent role exercised by a stronger dollar after the GFC, the authors also find statically significant regulatory and unconventional monetary policy effects after 2008, although these factors are temporary and 
vary across countries. In the Amador et al. (2019) study, a prominent role is deserved to the zero lower bound environment. The inverse relationship between nominal interest rates and the deviations is observed concomitant to a positive relation between deviations and the size of foreign reserves, for most of the G10 currencies. This empirical finding is attributed to the fact that monetary authority can sustain a positive deviation by accumulating a sufficiently large position in foreign assets, through interventions on the foreign exchange market. Our contribution to this literature regards on empirically capture the dynamics of an FXI shock on the CIP deviations. 


\section{2}

\section{Methodology}

In order to capture the foreign exchange intervention dynamics on the covered interest parity, we employ two different methodologies. First, we present the ArCo methodology developed by Carvalho et al. (2018). ArCo belongs to the counterfactual class of analysis, showing two main differences with the canonical Synthetic Control developed by Abadie et al. (2010): it is more appropriated to deal with time series and ArCo does not require that the interest variable relies on a convex hull combination of peers.

Then, we present the assumptions we use to build the impulse response functions using Local Projection of Jordà (2005). Still, we follow closely Romer and Romer (2010) and Ramey and Zubairy (2018) by using identified shocks on the IRF construction.

\subsection{1}

\section{Artificial Counterfactual (ArCo)}

To implement the methodology in $R$ language, we use the package developed by Fonseca et al. (2017) ${ }^{1}$.

Let $\mathbf{y}_{i t}=\left(y_{i t}^{1}, \ldots, y_{i t}^{q_{i}}\right)^{\prime} \in \mathbb{R}^{q_{i}}$ be the set of all observable variables, where $i$ indexes the countries, $t=1, \ldots, T$ the days and $q_{i}$ the number of variables per country. Let also $\mathcal{D}_{t}$ be a binary variable assuming one when the country is exposed to the intervention and zero otherwise. For the specific case of Brazil, we have $\mathbf{y}_{B R, t}=\mathcal{D}_{t} \mathbf{y}_{B R, t}^{(1)}+\left(1-\mathcal{D}_{t}\right) \mathbf{y}_{B R, t}^{(0)}$.

Then, the interventions can be represented ${ }^{2}$ by

$$
\mathbf{y}_{B R, t}^{(1)}=\left\{\begin{array}{c}
\mathbf{y}_{B R, t}^{(0)}, \quad t=1, \ldots, T_{0}-1 \\
\delta_{t}+\mathbf{y}_{B R, t}^{(0)}, \quad t=T_{0}, \ldots, T
\end{array}\right.
$$

where $\left\{\delta_{t}\right\}_{t=T_{0}}^{T}$ is a deterministic sequence and $T_{0}$ represent the period of intervention. As $\mathbf{y}_{B R, t}^{(0)}$ is not observable after $T_{0}$, consider the approximating model for $\mathbf{y}_{t}$.

${ }^{1}$ For implementation of the ArCo package in the $R$ language, we follow closely the Fonseca et al. (2018) manual.

${ }^{2}$ The methodology developed by Carvalho et al. (2018) allows for a more general framework. The estimation can be done for some arbitrary function of $\mathbf{y}$, which will depend on the moment of interest. We use the simplest specification since we are only interested in effects on the mean. 


$$
\mathbf{y}_{B R, t}^{(0)}=\mathcal{M}\left(\mathbf{Y}_{0, t}, \theta_{0}\right)+\varepsilon_{t}, \quad t=1, \ldots, T
$$

The $\mathbf{Y}_{0, t}$ in Equation 2-2 correspond to the collection of all the untreated units' observable $\mathbf{Y}_{0, t}=\left(\mathbf{y}_{2, t}, \ldots, \mathbf{y}_{n, t}\right)$, where $n$ represent the number of countries in the sample. Our main objective is to consistently estimate $\widehat{\delta}_{t}=$ $\mathbf{y}_{B R, t}-\mathcal{M}\left(\mathbf{Y}_{0, t}, \widehat{\theta}_{0}\right)$, for $t=T_{0}, \ldots, T$. Carvalho et al. (2018) demonstrate that $\widehat{\theta}_{0}$ is a consistent estimator for $\theta_{0}$ using only observations before the intervention.

ArCo methodology allows for quite general choice of $\mathcal{M}\left(\mathbf{Y}_{0, t}, \theta_{0}\right)$. A natural choice is the usual ordinary least square (OLS), which we use to estimate the daily regressions. However, when we look at weekly data, in our robustness test, the pre-treatment sample becomes quite short. We tackle this problem by estimating $\mathcal{M}\left(\mathbf{Y}_{0, t}, \theta_{0}\right)$ using LASSO, which enables us to work in a high dimension environment. We use the $R$ package developed by Vasconcelos (2017), which selects the $\lambda$ in LASSO by looking at the lowest Bayesian Information Criteria (BIC).

In this paper, the particular $\mathbf{y}_{B R, t}^{(0)}$ we are interested in is the CIP deviations from the Brazilian real against the American dollar. However, a problem we face in estimating this kind of equation is the difficulty in explains these deviations. Even controlling for several different variables related to the parity, the poor fit in the pre-intervention observations may affect the quality of the post-intervention estimation.

We then ran a robustness exercise, in the spirit of Fama (1984), and also used in some recent papers [Cerutti et al. (2019), Engel et al. (2019)], consisting in split the CIP between the Forward Premium (FP) and the Interest Rates Differential (IRD) to estimate equations like Equation 2-3 bellow ${ }^{3}$.

$$
\mathbf{F P}_{B R, t}^{(0)}=\beta \mathbf{I R D}_{B R, t}+\mathcal{M}\left(\mathbf{Y}_{0, t}, \theta_{0}\right)+\varepsilon_{t}, \quad t=1, \ldots, T
$$

Fama (1984) adopted this strategy to verify whether the CIP holds or not for a given pair of countries, by regressing the FP on the IRD. If the parity holds, it is expected an estimated intercept equal to zero and the estimated IRD coefficient $\beta$ equals one ${ }^{4}$. The advantage of this approach, in our context, is the higher explanatory power compared to the CIP alone, as IRD explains most of the FP.

The null hypothesis of interest assumes the form of Equation 2-4.

\footnotetext{
${ }^{3}$ By definition, CIP is equal to the interest rate differential minus the forward premmium. See the Section 3 for further details.

${ }^{4}$ The intercept is not showed explicitly in Equation 2-3 because the notation assumes that $\mathcal{M}\left(\mathbf{Y}_{0, t}, \theta_{0}\right)$ contains the intercept term.
} 


$$
\mathcal{H}_{0}: \Delta_{t}=\frac{1}{T-T_{0}+1} \sum_{t=T_{0}}^{T} \delta_{t}=0
$$

Carvalho et al. (2018) build the Equation 2-4 statistics using $\widehat{\delta}_{t}$. Moreover, the authors construct the confidence interval for $\widehat{\Delta}_{t}$, which we use to evaluate if the program delivered a higher CIP deviation after the intervention, on average, for a given confidence level.

Lastly, we are aware that using the Artificial Counterfactual methodology, a straightforward exercise would be to compare the results with the most traditional counterfactual methodology, the Synthetic Control (SC), developed by Abadie et al. (2010). However, the Brazilian CIP deviations violate a crucial hypothesis of SC by lying outside the convex hull formed by the peers. Figure 1.1 illustrate this fact: the 12-month Brazilian CIP deviations is higher than any peer deviation during several periods. This violation compromises the SC results since no convex combination of CIP deviation from the control group can achieve the Brazilian deviation. Even if we could consistently estimate SC equations, Carvalho et al. (2018) points to the advantage in using ArCo instead when working in a time series environment, since the Abadie et al. (2010) methodology do not account for the time dimensions of the data.

\subsubsection{1 \\ Identification}

A crucial assumption required by the ArCo is that peers cannot be affected by the intervention ${ }^{5}$. In our context, the Brazilian Central Bank (BCB) handled these FX interventions to smooth movements in the USDBRL caused by the taper tantrum.

In this context, for a country belongs to the control group it is sufficient that no FX intervention had been ruled by the respective central bank during the period in the analysis. An implicit hypothesis we also assume is that interventions in Brazil do not affect the parity in other countries in the control group, which seems reasonable since Brazil does not represent a large financial market.

However, assessing whether or not a country has intervened in the foreign exchange market is not a trivial exercise. As discussed by Dominguez (2019), central banks are not always clear how and when they intervene in their local foreign exchange market.

Then, to construct a list of countries eligible for the control group, we mix countries used by Dominguez (2019) and Chamon et al. (2017). The only country used by both papers and not here is Colombia. According to Hofmann

\footnotetext{
${ }^{5}$ In fact, this hypothesis is also required by the Synthetic Control of Abadie et al. (2010).
} 
et al. (2019), the Colombian monetary authority ruled pre-announced FX auctions during 2011 and 2014, aiming to increase its international reserves. A caveat regarding Turkey is the fact that the Central Bank of Turkey had intervened in a single day selling almost 3 bn USD on Jan 23, 2014. We do not believe this single auction would affect our identification because we see as an isolated event since no intervention has occurred after this day and previous interventions occurred only in Jan 2012. Moreover, we see Turkey as an important peer of Brazil, mainly due to their similar interest rates differential, so that we decide to keep the country in the analyses, following Dominguez (2019) and Chamon et al. (2017).

Although both papers deal only with emerging market economies, we add to the control group some developed economies usually studied in the CIP deviations literature, also known as the G10 ${ }^{6}$ currencies, since our daily data allows a higher number of variables. For the case of weekly data, the LASSO circumvent any trouble of adding more variables in the estimation. After analyzing the actions of its central banks during 2013 and 2015, we conclude that only Australia, Canada, Eurozone, and Japan are eligible.

Considering all the points mentioned above, the thirteen countries that compose the control group are: Australia, Canada, Chile, Czech Republic, Eurozone, Hungary, India, Israel, Japan, Korea, Mexico, Philippines, and Turkey.

Finally, the identification hypotheses also affect the pre-treatment period. During 2012, the BCB intervened through swaps for several days. In May 2012, it sold around 5.5 bn USD; in June, more than 10 bn USD and between November and December, more 5.5 bn USD. Then, we choose to restrict our analysis for the year of $2013^{7}$ as we discuss in detail in the next section.

\subsection{2}

\section{Local Projection}

A disadvantage in estimating the ArCo statistics regards the lack of information about the exact effect of an FXI on the CIP deviation. For estimating the aggregate average impact, ArCo even uses the intervention observations.

Aiming to tackle this problem, we use the Jordà (2005) Local Projection (LP) to estimate impulse response functions (IRF's) of CIP deviations' reaction

\footnotetext{
${ }^{6}$ According to Du et al. (2018), the G10 currencies correspond to Australian dollar, Canadian dollar, Swiss franc, Danish krone, British pound, Euro, Japanese yen, Norwegian krone, New Zealand dollar and Swedish krona.

${ }^{7}$ There was a single intervention ruled on March 27, 2013, when BCB sold almost 1 bn USD, which we consider as an isolated event. Nevertheless, we test our results excluding this specific day of the sample, and the results remain unchanged statistically.
} 
to an intervention. We estimate the responses in $R$ language using the package developed by Adämmer (2019).

Among the advantages of LP cited by Jordà (2005), we highlight the robustness to misspecification and the inference, which follows the standard OLS procedures. The only concern regarding the inference is the error serial correlation. Then we use the Newey and West (1987) robust standard errors, as recommended by Jordà (2005).

We follow closely the approach of Romer and Romer (2010) and Ramey and Zubairy (2018) by identifying the shock. Let consider the following framework

$$
\mathbf{C I P D}_{t}=\alpha+\beta \mathbf{C F}_{t}+\Theta \mathbf{C R}_{t}+\varepsilon_{t}
$$

where $\mathbf{C F}_{t}$ represents the capital flows and $\mathbf{C R}$ the country risk in the period $t$. CIPD ${ }_{t}$ is the deviation observed from the parity in the same period. Obviously, the effects are not only simultaneous but for simplicity, we ignore the dynamics for now.

Because the CIP is an arbitrage condition, it is closely related to the complete market hypothesis. Any restriction on the capital flows may affect the players' capacity to negotiate the assets involved in the parity, distorting prices and leading to deviations. The second component is usually attributed to the CIP deviations observed in emerging markets currencies. It contemplates risks of credit, convertibility, liquidity, and sovereign defaults.

The term $\varepsilon_{t}$ includes other factors that transiently affect the deviations. Recent literature assigns as candidate causes the banking regulations, the USD strengthening and the zero lower bound environment for the deviations occurred after 2008 GFC, as discussed in Section 1.0.1, and might be correlated with each other.

$$
\varepsilon_{t}=\sum_{i=1}^{K} \varepsilon_{t}^{i}
$$

At the same time, most of these factors also affect the capital flow among countries. Additionally, FXI is a measure adopted by central banks to correct dysfunctionalities on the exchange market caused by abrupt capital flows change. In the taper tantrum context, as mentioned earlier, FXI was adopted to circumvent the massive capital outflow caused by the quantitative easing measures' withdraw, as one example. Then, consider the following specification for the capital flow variable.

$$
\mathbf{C F}_{t}=\sum_{i=1}^{K} \varepsilon_{t}^{i}+\mathbf{F X I}_{t}
$$

where $\varepsilon_{t}^{i}$ are the same as before. $\mathbf{F X I} \mathbf{I}_{t}$ represents the foreign exchange inter- 
vention, which in our case assumes interventions in the forward and the spot market. This specification implies that interventions are exogenous to the other factors that transiently affect the deviations. We believe this hypothesis holds true since the FXI aims only to give foreign exchange market liquidity. This necessity is triggered by reasons as internal political events and/or market stress observed along a day, in events when BCB decides to sell dollars. The purchase of foreign currencies is motivated by good market conditions and the monetary authority desire to accumulate reserves ${ }^{8}$.

Then, replacing 2-7 and 2-6 on 2-5

$$
\mathbf{C I P D}_{t}=\alpha+\beta\left[\sum_{i=1}^{K} \varepsilon_{t}^{i}+\mathbf{F} \mathbf{X I} \mathbf{I}_{t}\right]+\Theta \mathbf{C R}_{t}+\sum_{i=1}^{K} \varepsilon_{t}^{i}
$$

Adding the dynamics interaction and rearranging the terms, the specification takes the form of Equation 2-9 below. We use as proxies for country risk log difference of 5-year CDS and VIX, and the bid-and-ask spread for USDBRL. We control both $\mathbf{C I P D}_{t}$ and $\mathbf{C R}_{t}$ with 5 lags, capturing the last week's movements. The IRF is then defined as the sequence of all coefficients related to the shock variable $\left\{\beta^{h}\right\}_{h=0}^{H}$, where $h$ index the horizons.

$$
\mathbf{C I P D}_{t+h}=\alpha+\Omega^{h}(L) \mathbf{C I P D}_{t-1}+\Theta^{h}(L) \mathbf{C R}_{t-1}+\beta^{h} \mathbf{F} \mathbf{X I}_{t+h}+u_{t}
$$

where $u_{t}$ is a functions of $\varepsilon_{t+h}^{i}$ and it is uncorrelated to the interventions.

Although the differences in IRF construction, Plagborg-Møller and Wolf (2019) argues that LP and VAR estimations are the same for a less restrictive set of hypotheses than the correct modeling of DGP, as proposed by Jordà (2005). According to the authors, the only trade-off researchers face between the two techniques is that LP produces low bias estimations, while VAR has a lower variance. Plagborg-Møller and Wolf (2019) still show the estimations are equivalent up to a settled horizon.

Summarizing, we claim that the BCB do not look at the CIP when decide to intervene or not, it only consider movements on the exchange rates caused by liquidity problems, and the effect is given through this channel, of capital flows movement. Note this is not the case when studying the FXI impacts of the exchange rates [Chamon et al. (2017), Hofmann et al. (2019)].

\footnotetext{
${ }^{8}$ For a detailed discussion about the hypothesis that must hold for consistently estimate the dynamics, see Stock and Watson (2018).
} 


\section{Data}

The currencies and interest rates data used to calculate the CIP deviations come from Thomson Reuters. We also use data of 5-year CDS (Credit Default Swap) and equity indices in ArCo. A complete list of the variables can be found in Appendix A. In the robustness exercise, we use weekly data of equity and bond flows per country, in USD, from Haver Analytics.

To estimate the Local Projection impulse response functions, we use daily data of swap interventions, provided by the AC Pastore, and spot interventions series from BCB website, from 2009 until 2020.

\subsection{1}

\section{The Program of Daily FX Intervention}

On May 22, 2013, after six years of Quantitative Easing (QE), the then FED-chairman Ben Bernanke first revealed the FOMC's plan to step down the pace of the ongoing expansionary monetary policy, in what becomes known as the taper tantrum.

For the emerging markets, like Brazil, the end of the QE represented a massive outflow of capital. In the specific case of the Brazilian real, it was followed by a $10 \%$ depreciation in the month after the announcement, the strongest effect among the emerging markets economies, as pointed out by Eichengreen and Gupta (2015). Strong currency depreciation could negatively impact the local private sector, which held a high debt in dollars, hired in the context of capital inflow followed by the GFC, as explained by Domanski et al. (2016). Then, to strike the consequences of the capital outflow, the Brazilian Central Bank began to intervene in the FX market, using forward derivative instruments.

Among the advantages of intervening in the forward exchange market, Nedeljkovic and Saborowski (2019) cite, as the most relevant at that time, the fact that forward interventions do not imply in international reserves changes, because no payments are required at the time the contracts are negotiated. At the maturity, however, the Central Bank pays the USDBRL variation of the period plus the ex-ante on-shore dollar rate, the Cupom Cambial. On the other hand, the counterpart pays the ex-post variation of domestic interest rate DI. 
Thereby, the Central Bank offers a hedge against USDBRL variations to the market players without the necessity of buying spot dollars.

On May 31, 2013, BCB started to sell swap contracts in a discretionary way: the central bank made auctions only in days it thought was necessary. However, these interventions had not achieved the results the monetary authority was expecting, and on August 22 BCB announced a major program of daily interventions until, at least, the end of 2013. Every working day, the BCB sold USD $500 \mathrm{mn}$ worth of currency forward through swaps. Moreover, the program also contemplates a weekly USD 1 billion repurchase agreement (repo) auction offer, on Fridays.

Due to its good performance, the program was extended three times in the following months, ending only on March 31, 2015. These extensions are from our particular interest because it will guide the way we partition the sample. First, we separate the pre-intervention sample in two periods: the period where no intervention was ruled and the period where only discretionary interventions happened. The objective is to understand if there is an effect on interventions or in $\mathrm{BCB}$ compromise in intervening. We interpret these two possible effects as analogous to the portfolio balance and signaling channels described by Sarno and Taylor (2001). Then we analyze if the extensions announcements had any impact on CIP deviations, splitting the post-intervention sample, according to the respective dates.

In Figure 3.1 we show the sub-samples we work with. We label each one as "Sample". The group where no intervention was ruled and the period pre-program announcement are represented by Samples 1 to 5 and Samples 6 to 9, respectively, in Figure 3.1. Sample 1 we use to evaluate the efficiency of intervening or not while in Sample 6, we evaluate the efficiency of the program. Note that the post-intervention period is the same for Sample's 2 and 6, 3 and 7, 4 and 8 , and 5 and 9 . We highlight the dates of interesting, replicating in the top, middle and bottom of the table.

One implication of this subsampling is the number of observations in each Sample. Using daily data, Samples 1 to 5 have 100 days, while Sample 6 to 9 has 159. When we look at the weekly data however, the number of observations shrinks to 21, in the first group, and 33 and the second group. This fact leads us to estimate weekly models using LASSO in the ArCo first step, as we will explain in Section 4. 
Figure 3.1: Periods of Analysis

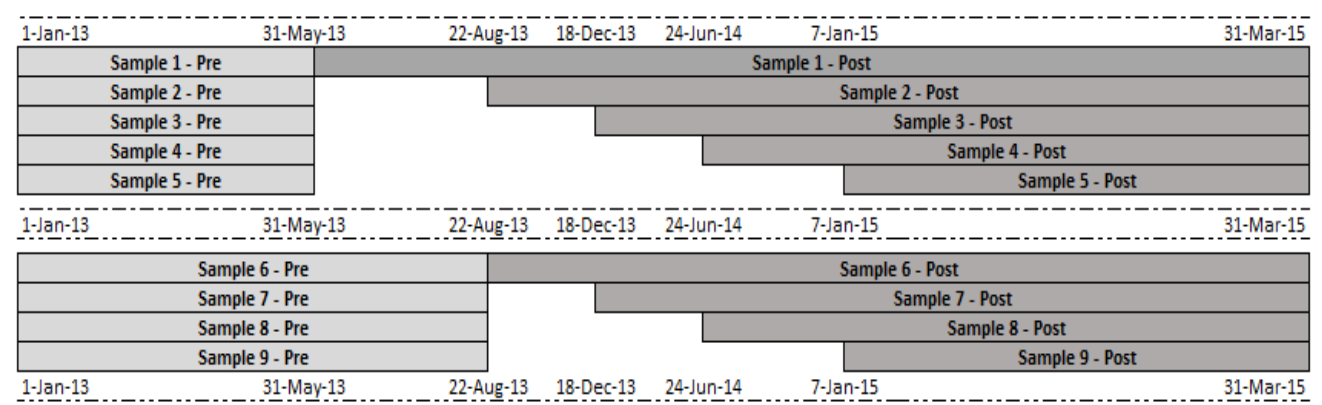

The intervention day for Sample 1 to 5 is when BCB began to intervene in a discretionary way, on 31 May 2013. The post-intervention period for Sample 2 is the program announcement; for Sample 3 is the first extension, on 18 Dec 2013; Sample 4 is the second extension, on 24 Jun 2014; and Sample 5 is the last extension, on 7 Jan 2015. For Sample 6 to 9, the intervention day is when $\mathrm{BCB}$ announces the major program of daily swap sales. The post-intervention periods are analogous to the Sample 1 to 5.

\subsection{2}

\section{CIP Deviations}

According to the covered interest parity condition, for any two currencies, their interest rate differential for some maturity $k$ must be equal to their forward premium, evaluated as the difference between the forward exchange rate, of maturity $k$, and the spot exchange rate. As it consists of a no-arbitrage condition, any deviation represents a profitable risk-free opportunity, since all future values are pre-determined at the time of the transaction.

Let $i_{t, t+k}$ represents the domestic interest rate of maturity $k$ and $i_{t, t+k}^{*}$ represents the foreign interest rate; $S_{t}$ is the spot exchange rate and $F_{t, t+k}$ the corresponding forward price, both defined as the amount of domestic currency necessary to buy one dollar. Then, the CIP condition can be represented as

$$
S_{t}\left(1+i_{t, t+k}\right)^{k}=F_{t, t+k}\left(1+i_{t, t+k}^{*}\right)^{k}\left(1+x_{t, t+k}\right)^{k}
$$

where $x_{t, t+k}$ represents the deviations from CIP for a maturity $k$. It is usual in the literature - and more convenient - to represent the equation in log terms.

$$
\ln \left(1+x_{t, t+k}\right)=\left\{\ln \left(1+i_{t, t+k}\right)-\ln \left(1+i_{t, t+k}^{*}\right)\right\}-\rho_{t, t+k}
$$

The first component of Equation 3-2 represents the interest differential and $\frac{f_{t, t+k}-s_{t}}{k} \equiv \rho_{t, t+k}$ represents the forward premium. Note that we adjust the maturity in the forward premmium.

Regarding the variables used to calculate the CIP deviations, we follow Du et al. (2018) and use the interbank interest rates, with $i_{t, t+k}^{*}$ representing the USD LIBOR. Because the LIBOR exists for the maturity of up to one 
year, we restrict our analysis to the maturities $k=\{1,3,6,9,12\}$ months. ${ }^{1}$

Although the calculation of CIP for developed economies is straightforward, when looking at emerging economies some problems arise. Chile does not have usual forward currencies contracts, so we use NDF (Non-Deliverable Forward) contracts for calculating their deviations. Still, Brazil has issues regarding currency forward derivatives and interest markets. As Brazil holds a prominent position in our analyses, we reserve the next subsection to explain how its future exchange rate market works.

\subsubsection{1}

\section{Brazil}

Although Brazil has a usual forward dollar market, the liquidity in this market is concentrated only on the shorter maturity of one month ${ }^{2}$, which arise problems when we look at longer maturities, as is usual in the CIP literature.

For historical reasons, Brazil has developed a market of on-shore dollar interest rates, known as Cupom Cambial, and it can be defined as the yield, in dollars, for an on-shore investment applied in Brazilian reais (BRL). Then, the price of Cupom Cambial consists of the local interest rate - $\mathrm{DI}^{3}$ - minus the expected depreciation of the local currency against de dollar. For this reason, Cupom Cambial is commonly used to extract the market expectation of future BRLUSD quotations.

In our study, we follow previous studies in calculating the CIP deviation for Brazil using only the Cupom Cambial and the LIBOR in dollars. It is important to note that using the Cupom Cambial instead of the future dollar does not affect the CIP deviation measure since market operators could arbitrage any wedge between these two markets. Cieplinski et al. (2014) defines the Cupom Cambial $i_{t, t+k}^{c}$ of maturity $k$ as

$$
\left(1+i_{t, t+k}^{c}\right)^{k}=\frac{\left(1+i_{t, t+k}\right)^{k}}{\frac{F_{t, t+k}}{S_{t}}}
$$

Then, from equations 3-2 and 3-3, we can define the CIP deviation in Brazil, against the US dollar, as

$$
\ln \left(1+x_{t, t+k}\right)=\ln \left(1+i_{t, t+k}^{c}\right)-\ln \left(1+i_{t, t+k}^{*}\right)
$$

\footnotetext{
${ }^{1}$ The study of CIP for longer maturities is calculated by the spread on the cross-currency basis swap. See Du et al. (2018) for details.

${ }^{2}$ Actually, the one-month forward market is more liquid than the spot market in Brazil, since only banks can operate in the spot market, and even the prices are formed first in the forward market than the spot market, as shown by Ventura and Garcia (2012).

${ }^{3}$ Depósito Interbancário, the domestic interbank deposits.
} 
where $i_{t, t+k}^{*}$ is the LIBOR quoted in dollars. Note that, for extracting the Brazilian forward premium of maturity $k$, we can just subtract the local interest rate DI from the Cupom Cambial.

Table 3.1: CIP Deviations - Descriptive Analyses

\begin{tabular}{l|llll|llll|lllll|lll}
\hline \multirow{2}{*}{ Country } & \multicolumn{1}{|c|}{ 1 Month } & \multicolumn{1}{|c|}{ 3 Month } & \multicolumn{4}{c|}{ Month } & \multicolumn{4}{c}{12 Month } \\
& Mean & SD & Max & Min & Mean & SD & Max & Min & Mean & SD & Max & Min & Mean & SD & Max & Min \\
\hline Australia & -0.05 & 0.75 & 4.67 & -4.39 & -0.01 & 0.26 & 1.63 & -1.55 & 0.02 & 0.15 & 0.88 & -0.77 & 0.05 & 0.12 & 0.57 & -0.43 \\
Brazil & 0.88 & 0.57 & 3.57 & -0.93 & 0.91 & 0.38 & 2.14 & 0.04 & 1.11 & 0.38 & 2.35 & 0.32 & 1.22 & 0.48 & 2.75 & 0.39 \\
Canada & 0.18 & 0.66 & 3.72 & -2.86 & 0.15 & 0.23 & 1.42 & -0.77 & 0.14 & 0.12 & 0.84 & -0.27 & 0.04 & 0.09 & 0.46 & -0.96 \\
Chile & -0.22 & 0.53 & 0.82 & -2.34 & 0.08 & 0.34 & 0.96 & -1.05 & 0.33 & 0.25 & 0.96 & -0.30 & 0.24 & 0.30 & 0.81 & -3.67 \\
Czech Rep & 0.28 & 0.61 & 3.56 & -5.14 & 0.29 & 0.21 & 1.42 & -1.42 & 0.31 & 0.14 & 0.95 & -0.48 & 0.29 & 0.15 & 0.85 & 0.03 \\
Euro & -0.17 & 2.78 & 11.47 & -27.86 & 0.02 & 0.91 & 4.04 & -8.39 & 0.07 & 0.46 & 2.09 & -3.98 & 0.09 & 0.25 & 1.12 & -1.79 \\
Hungary & 0.59 & 0.87 & 5.46 & -3.40 & 0.65 & 0.39 & 2.32 & -0.60 & 0.68 & 0.53 & 6.43 & -0.28 & 0.45 & 0.22 & 0.96 & -0.45 \\
India & -0.31 & 0.92 & 5.08 & -4.87 & 0.21 & 0.63 & 2.75 & -1.75 & 0.56 & 0.69 & 2.86 & -1.03 & 0.99 & 0.70 & 3.54 & -0.27 \\
Israel & 0.13 & 0.63 & 3.55 & -3.01 & 0.18 & 0.26 & 1.22 & -0.97 & 0.13 & 0.19 & 0.83 & -0.54 & 0.00 & 0.17 & 0.65 & -0.48 \\
Japan & 0.28 & 0.59 & 3.67 & -2.90 & 0.25 & 0.21 & 1.53 & -0.80 & 0.26 & 0.13 & 0.94 & -0.23 & 0.14 & 0.12 & 0.56 & -0.17 \\
Mexico & 0.10 & 0.87 & 3.00 & -6.00 & 0.30 & 0.32 & 1.52 & -1.87 & 0.28 & 0.19 & 1.18 & -0.75 & 0.14 & 0.12 & 0.48 & -0.49 \\
Philippine & 1.48 & 0.90 & 4.83 & -0.85 & 0.08 & 0.47 & 1.58 & -1.13 & -0.02 & 0.41 & 0.95 & -1.01 & 0.01 & 0.43 & 1.01 & -0.86 \\
South Korea & 0.24 & 0.47 & 2.61 & -6.48 & 0.38 & 0.26 & 1.16 & -1.90 & 0.49 & 0.18 & 1.05 & -0.61 & 0.60 & 0.15 & 1.23 & 0.09 \\
Turkey & 0.19 & 1.82 & 5.17 & -31.69 & 0.49 & 0.79 & 2.26 & -9.02 & 0.53 & 0.64 & 2.19 & -4.11 & 0.55 & 0.50 & 1.59 & -1.67 \\
\hline
\end{tabular}

CIP deviations are shown in \% per year. We use daily data from the day $\mathrm{BCB}$ begin to intervene, on May 31, 2013, until the last intervention, on March 31, 2015. All data is collected from Thomson Reuters Datastream. See Appendix A for further details.

In Table 3.1, some descriptive statistics of the CIP deviations are shown for every maturity and country in the sample. Some patterns can be observed in these statistics.

First, the shorter maturities are more volatile than the longer ones. Second, longer maturities tend, in general, to have a higher mean. These two facts are compatible with previous papers that analyze the CIP deviation phenomenon in the G10 currencies, as in Du et al. (2018) and Cerutti et al. (2019). Finally, emerging economies have shown, in general, a higher deviation. This is in line with the idea that there exist risks in investing in these countries, mainly country risk and convertibility risk since these markets are less liquid in general. For the case of Brazil, these facts are explained by Garcia and Didier (2003).

\subsection{3 \\ Interventions}

In the last ten years, the Brazilian Central Bank has used several instruments to intervene in the FX markets. After the 2008 GFC, it took advantage of the high inflow of capital to build up reserves, by purchasing American dollars in the spot market. This movement lasts until May 2012 and was responsible for an increase of 180 USD bn in the Brazilian international reserves $^{4}$, as shown in light red in Figure 3.2.

${ }^{4}$ On 9 May 2011, the international reserves accounted for 191 USD bn and 2 May 2012, for 374 USD bn, according to Brazilian Central Bank. 
Swaps interventions are shown in blue. The major program is represented the dark blue, between 2013 and 2015. Other interventions via swap were also used along with our sample. At the end of 2019, the BCB took advantage of its high international reserves level to operate by selling USD dollar in the spot market meanwhile it liquidate open swap contracts. More recently, in the capital outflow caused by the Covid-19 pandemic, it uses swap and spot sales to provide liquidity to the market.

Figure 3.2: Foreign Exchange Interventions
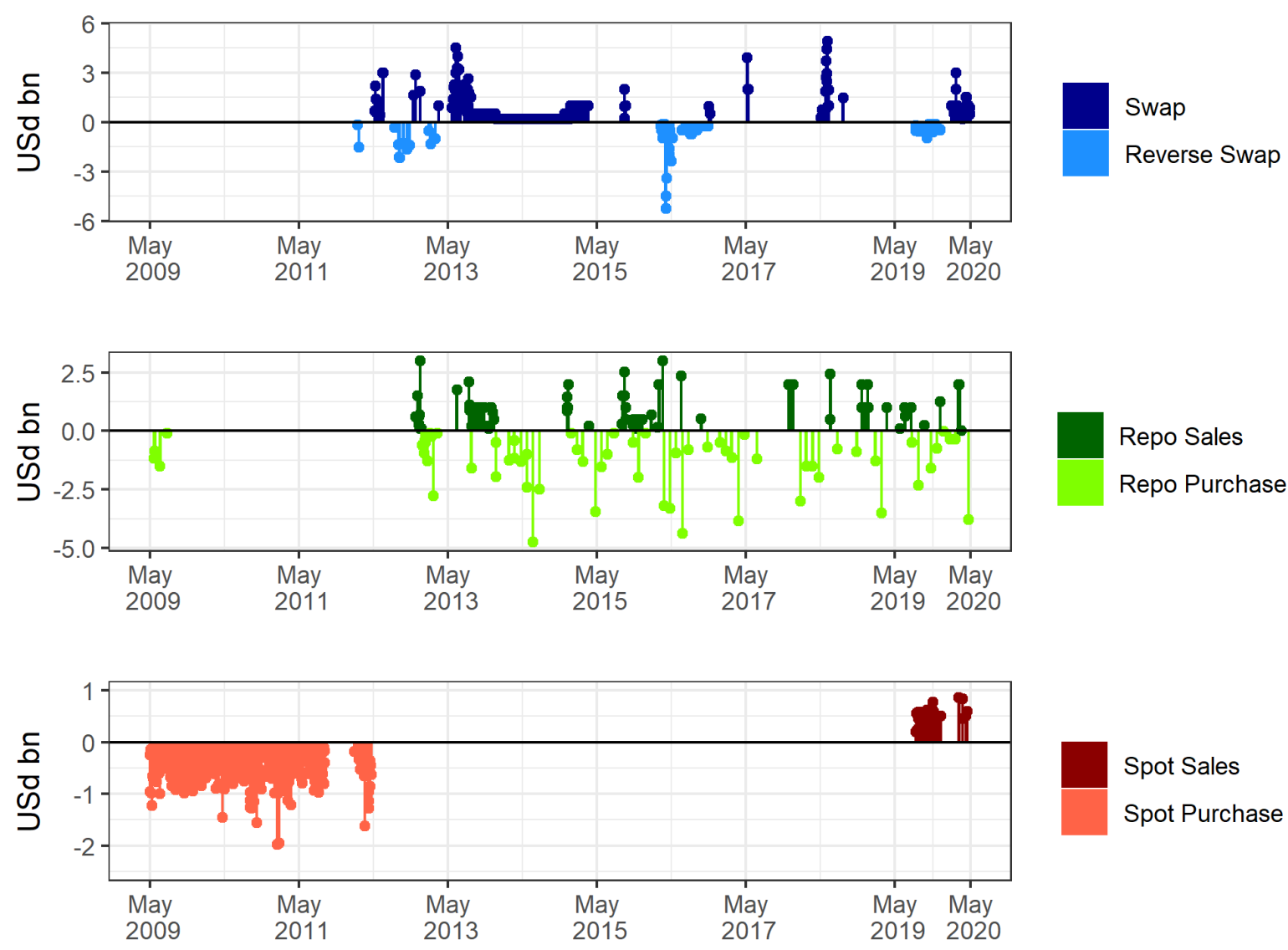

Spot Sales

Spot Purchase

Figure 3.2 shows the several instruments used by the Brazilian Central Bank to intervene in the FX market, as well as the direction of the interventions. The frequency is daily. The source is the BCB website.

Observing Figure 3.2, several specifications emerges for test with Local Projection. Beyond the primary question of whether forward interventions affect or not the CIP deviations, we also test if the reverse swap has the opposite effect. Still, we can test the Walker (2019) hypothesis that spot intervention does not affect the parity, for both cases of purchasing or selling foreign currency.

In this spirit, we delimit periods for testing the efficiency of each instrument used by the BCB, to match the periods these instruments were 
used in fact. For testing the swap intervention effect, we stick to the major 2013 program, explained earlier, and the auctions made after the Covid-19 crisis onset. Spot purchases are restricted to the years of 2009 to 2012. Spot sales were used only recently. Regarding the swap reverse, we have two distinct data, as can be visualized in Figure 3.2: a period in 2016, which we call Swap Reverse - 1, and the second period, used together with the spot sales more recently, Swap Reverse - 2 .

All these samples are detailed in Table 3.2. As can be seen in the Observations column, the sample size varies among each instrument, which leads to implications in the number of the horizon we estimate the IRF, considering the losses in terms of the degree of freedoms.

Table 3.2: Samples - Local Projection (LP)

\begin{tabular}{lcccc}
\hline Operation & Begins & Ends & Observations & Horizons \\
\hline Spot Purchases & 12 May, 2009 & 2 May, 2012 & 737 & 20 \\
Spot Sales & 23 Aug, 2019 & 23 Dec, 2019 & 84 & 10 \\
Reverse Swap - 1 & 1 Jul, 2016 & 8 Nov, 2016 & 89 & 10 \\
Reverse Swap - 2 & 21 Aug, 2019 & 20 Dec, 2019 & 85 & 10 \\
Swap & 31 May, 2013 & 31 Mar, 2015 & 462 & 20 \\
Swap 2 & 13 Feb, 2020 & 15 May, 2020 & 61 & 10 \\
Repo Purchases & 2 Jan, 2013 & 8 May, 2020 & 1806 & 20 \\
Repo Sales & 2 Jan, 2013 & 8 May, 2020 & 1806 & 20 \\
\hline
\end{tabular}




\section{4 \\ Results}

As mentioned in Section 2, we use two complementary approaches to capture the dynamics of CIP deviations through the counterfactual analysis. First, using the CIP and the second, in the spirit of Fama (1984), regressing the forward premium on the interest rate differential. We aim to better explain the pre-intervention sample by using these approaches.

Explaining the CIP deviations in the first step of ArCo is not a trivial exercise. As discussed earlier, several papers are trying to explain which factors are behind these deviations in the last few years. In this study, in a daily frequency data, this issue is accentuated. For this reason, we run tests for several different specifications, varying the exogenous controls, USD Index and VIX, and the variables common to all peers. For daily data, we test 32 different specifications, and for weekly data, 56, for each maturity and both CIP and Forward Premium models. Combining different specifications affect slightly the results, and we see this fact as robustness for our findings. The relation of the models used can be found in Table B.1 and B.2, for daily and weekly data respectively.

In Figure B.5 in the Appendix we show the Adjusted R-Squared for each specification, in the pre-treatment period, when the parameters were estimated. Two features from Figure B.5: first, longer maturities are better fitted, although the $R^{2}$ are barely higher than 0.50; and two, the Forward Premium equations have substantial higher coefficients of determination, reaching 0.8 in the one-year maturity, showing the importance of our robustness test.

A drawback in working with daily data is the lack of information about capital flows, an important feature regarding CIP since deviations from parity are expect to vanish through market players operating this arbitrage opportunity. To circumvent this issue, we use weekly data of equities and bond flows of Haver Analytics. However, some pre-treatment samples became significantly short, which lead us to estimate the pre-sample treatment parameters by LASSO. The results are corroborated by this robustness test and are shown in the following.

In the last subsection, we show the IRF using Jordà (2005) Local Projection. The results go in the same direction from ArCo models. Swaps 
interventions widen the parity, and this result is symmetric depending on the positions the BCB takes in the operation. Long-term maturities are more affected once again. The results regarding spot interventions, on the other hand, points to no effect on the parity.

\subsection{1}

\section{Daily ArCo}

The focus of our exercise is to look at the ArCo statistics. As explained earlier, it accounts for the difference between the counterfactual and the observed series on the post-treatment period. Carvalho et al. (2018) developed the inference properties of ArCo statistics, which allow us to build up a $95 \%$ confidence interval and check if it is statistically different from zero.

Figure 4.2 shows the ArCo statistics, as well as its $95 \%$ confidence interval, for Sample 1 - comparing when BCB intervened or not - and Sample 6 - evaluating the program announcement. Each color represents one of the 32 specifications. Our interest is not to identify each specification but to shed light on how the ArCo statistic changes depending on the variables we use to control. The order, from left to right, follows the specification 1 to 32 in Table B.1.

The first thing to note is that the statistics are quite homogeneous along we change the specification. Looking at the CIP in Sample 1, we see that the interventions ruled between May 31, 2013, until the end of the program does not seem to affect the CIP deviations, excepting a slightly negative impact on the maturity of 3 months. Although there is an increase in the FP of 12months, the IRD in the same period also increases monotonically, offsetting this effect.

On the other hand, results from Sample 6 tell a quite different story. Despite some net positive deviation in the 1-month maturity, a strong and statistically significant impact occurs in the 9 and 12-months maturities. The decrease in the forward premium goes in the same direction of the IRD increase, boosting the CIP deviation. The results for Sample 2, 3, 4, and 5 are quite similar do Sample 1. The same is true for Sample 7, 8, and 9 concerning Sample 6. The CIP results for those Sample's can be found in Figure B.1 and B.2, respectively, and are left in Appendix B. In addition to the OLS used for estimating pre-sample parameters, we also test LASSO in this daily data models and results remain the same, except by the heterogeneity among the specifications which is attenuated. Our main goal in testing LASSO was the concern about short pre-treatment samples ${ }^{1}$.

\footnotetext{
${ }^{1}$ In fact, the lowest sample we work with, discounted the degree of freedom, is 44 , in
} 
We interpret this stronger effect on longer maturity as a pattern related to the maturity of contracts offered by the Brazilian Central Bank. In Figure 4.1, we plot the average maturity of the contracts offered on the same day, since BCB usually offers more than one type of contract ${ }^{2}$. Along with the program, BCB offered longer contracts but never surpassing one year. Issuing long-term contracts puts upward pressure on the maturity of 9 and 12 months, specially.

The pattern of offering longer maturities is discussed by Craveiro (2019). According to the author, BCB began to issue longer maturities contracts to avoid overload the Cupom Cambial market in the short term. The drawback in offering long term contracts is an increase in the $\mathrm{BCB}$ exposition to variations in the exchange rate, which would imply at a higher cost.

Finally, we also test the models excluding the day of March 27, 2013. As discussed in Section 2.0.1.1, in this day BCB handled a single intervention, which we claim was not a response to the taper tantrum shock, and then should not affect our identification strategy. The results change only in the second decimal place, which remains our findings unchanged.

Figure 4.1: Average Maturity of the New Offered Swap Contracts

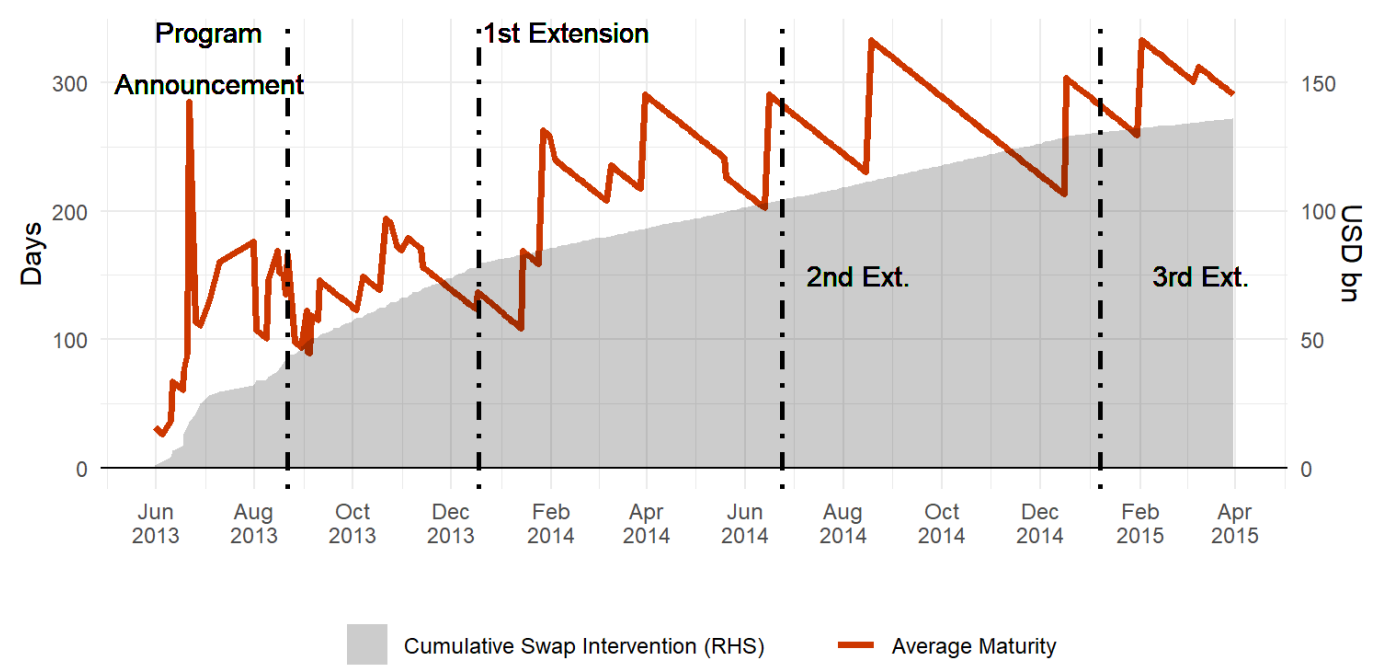

Figure 4.1 shows the average of maturities, measured in days, from new offered swap contracts by the Brazilian Central Bank. We use the average since for several days, BCB offered more than one type of contract, with different maturities. The valleys that occur after 2013, represent contracts offered with the same termination date. The cumulative swap intervention is the same shown in Figure 1.1 replicated here for convenience.

Sample 1 to 5 , when we estimate 56 parameters with 100 observations.

${ }^{2}$ We plot the simple average, but we also calculated the weighted average, considering the size of the contract. The patter is the same, but the series is noisier. 
Figure 4.2: Results - Daily ArCo

(a) CIF - Sinple 1

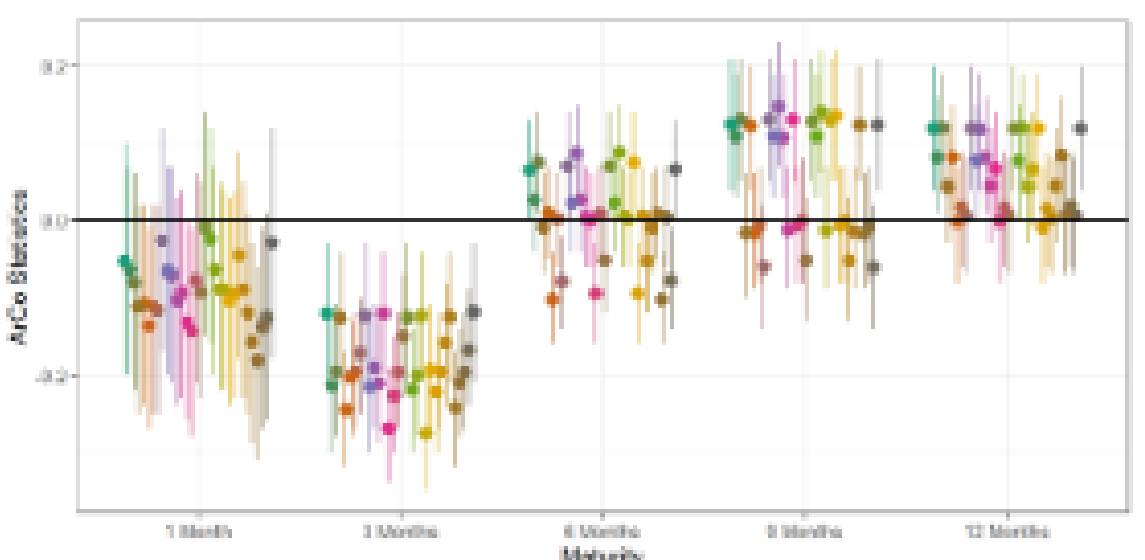

(c) CIP-Surplle 6

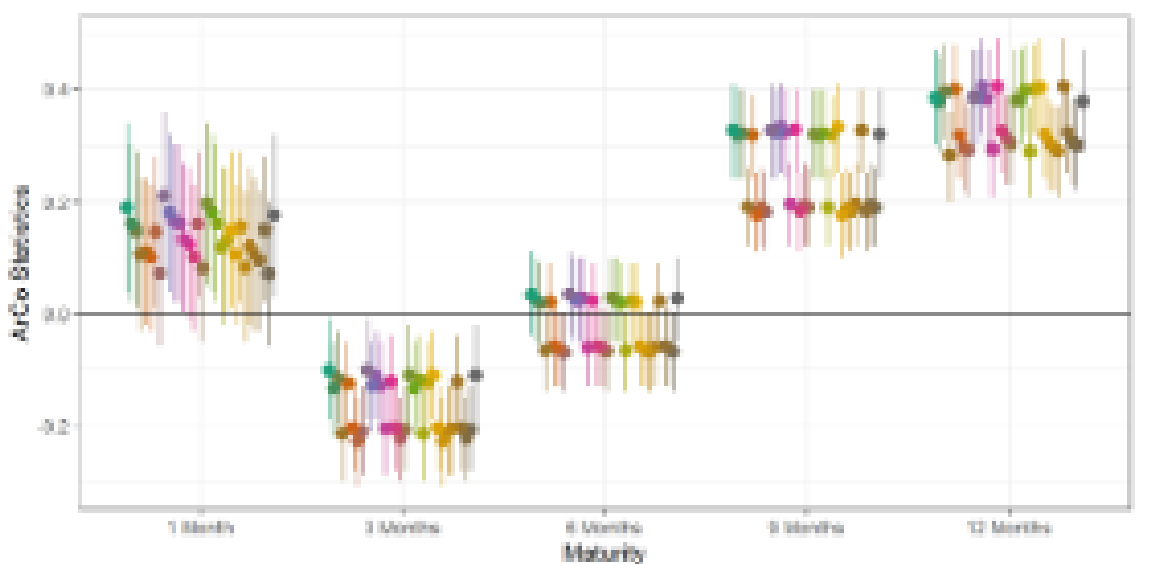

(b) $\mathrm{FI}^{2}$ - Siample 1

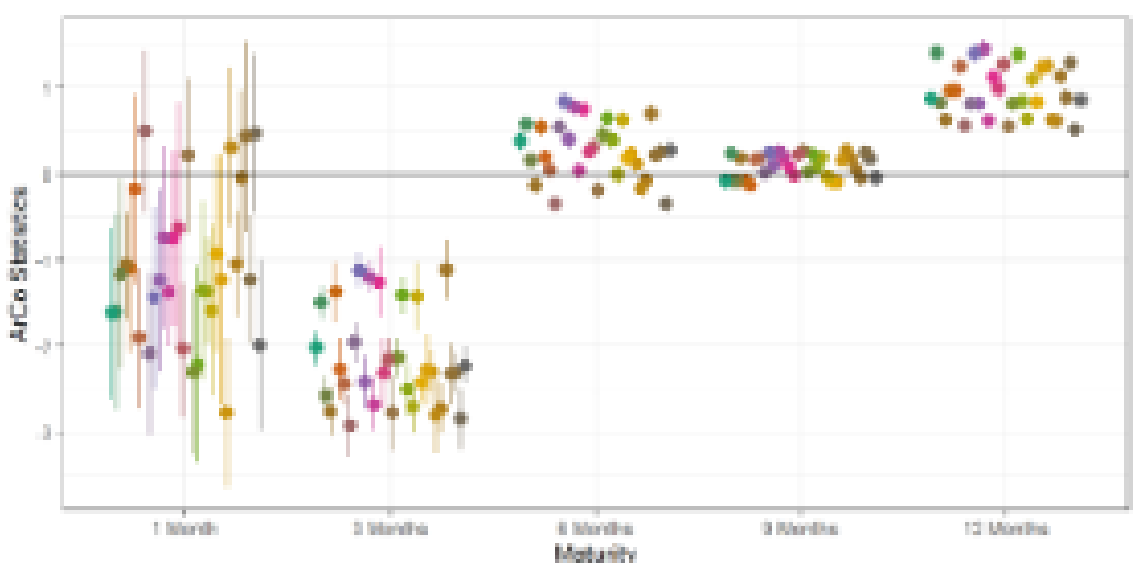

(d) FT Sample 6

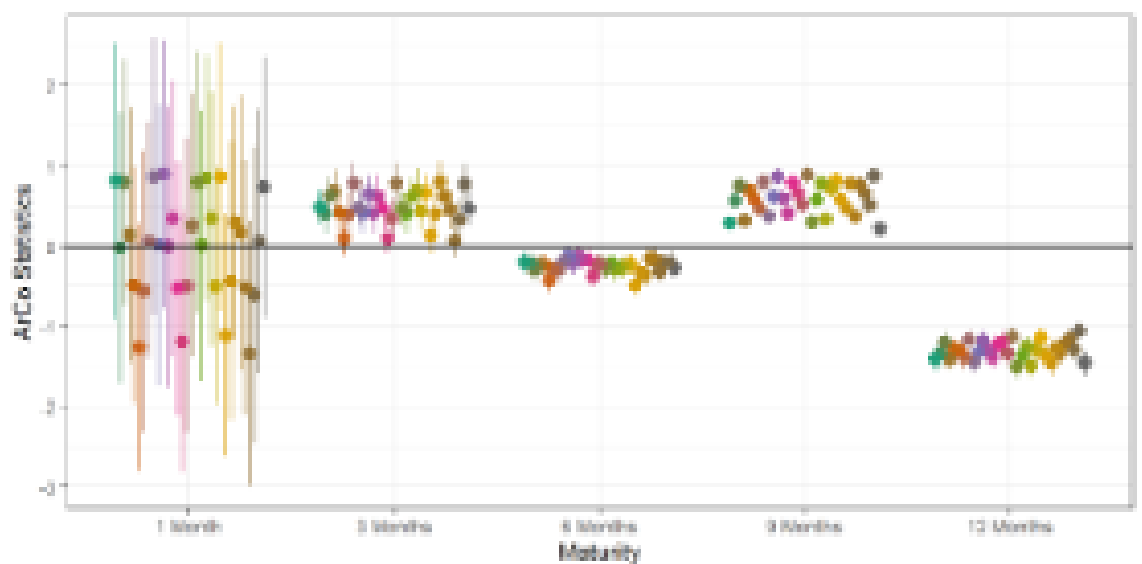

The colors represent an ArCo specification, as exposed in Table B.1. Each graphic represent a specific Sample division, as shown in Figure 3.1. The points represent the ArCo statistic, and the bars represent the 95\% confidence interval. Looking at the Forward Premium models, a negative statistic imply that the observed FP is lower then the estimated counterfactual, which in turn implies in a lower CIP deviation in the absence of intervention. 


\subsection{2}

\section{Weekly ArCo}

The main drawback of working with daily data is the lack of information about exchange flows. We tackle this problem by using weekly data of flows of dollars in bond and equity markets from Haver Analytics. To adjust the other variables for weekly frequency, we take the mean value of each one in that specific week.

A question that might arise is why not to use the weekly accumulated CIP deviations and the other variables instead of the mean. However, as explained in Section 3, we use the first difference in the log for CDS, Equities Indices, VIX, and USD Index, and the difference between the log of bid and the log of ask, to evaluate the spread. Meanwhile, we use the level of CIP deviations, since theory assumes it is a stationary variable. Then, to accumulate these variables would bring us some inconsistency, which we circumvent by using the mean.

Figure 4.3 shows the results using weekly data. The results corroborate the previous finding, by replicating the same pattern of longer maturities held the stronger effects. However, the analysis is less conclusive for the shorter maturities. The largest difference between daily and weekly exercises regards the homogeneity of the results: ArCo statistics are more sparse in the later, as became clear comparing Figures 4.2 and 4.3 . 
(a) CIP - Sample 1

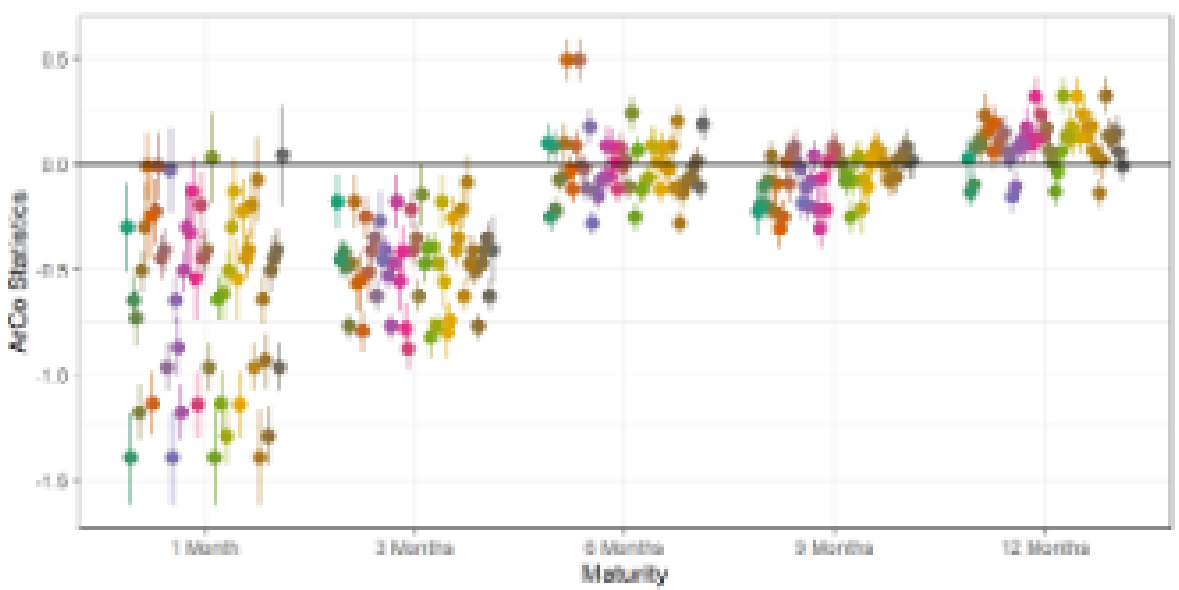

(c) CIP - Sample 6

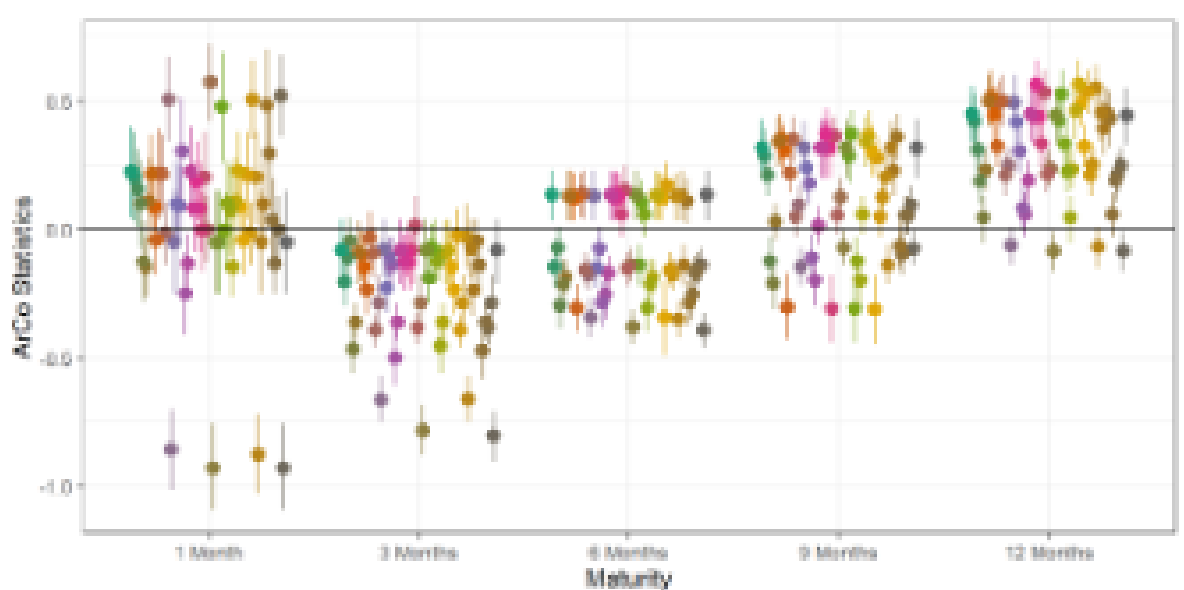

(b) FP - Sample 1

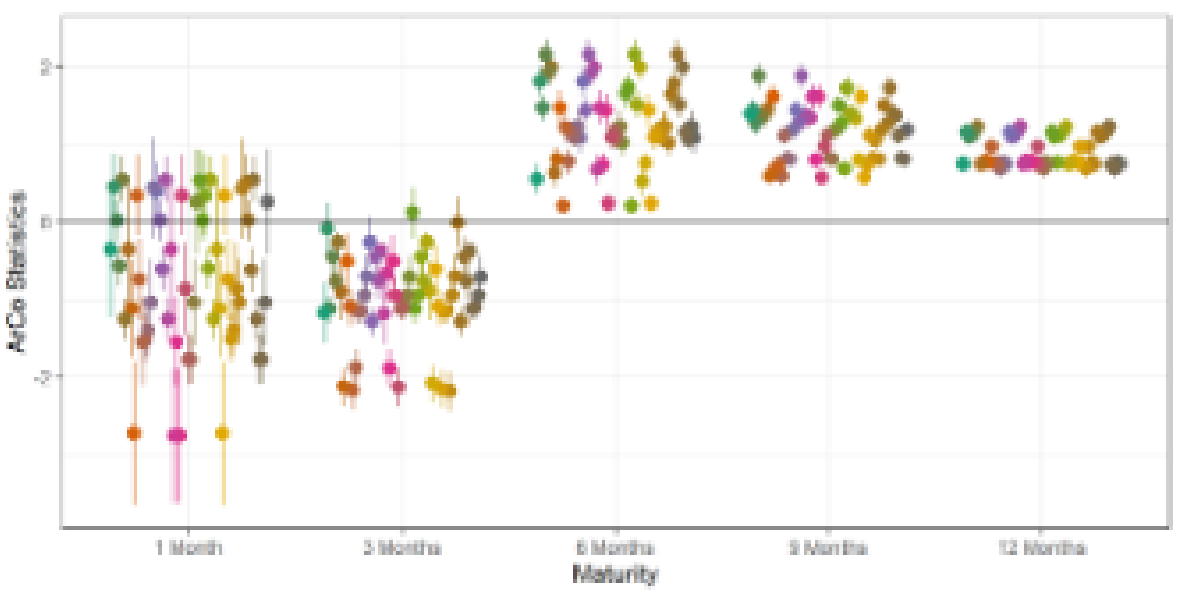

(d) FP - Sample 6

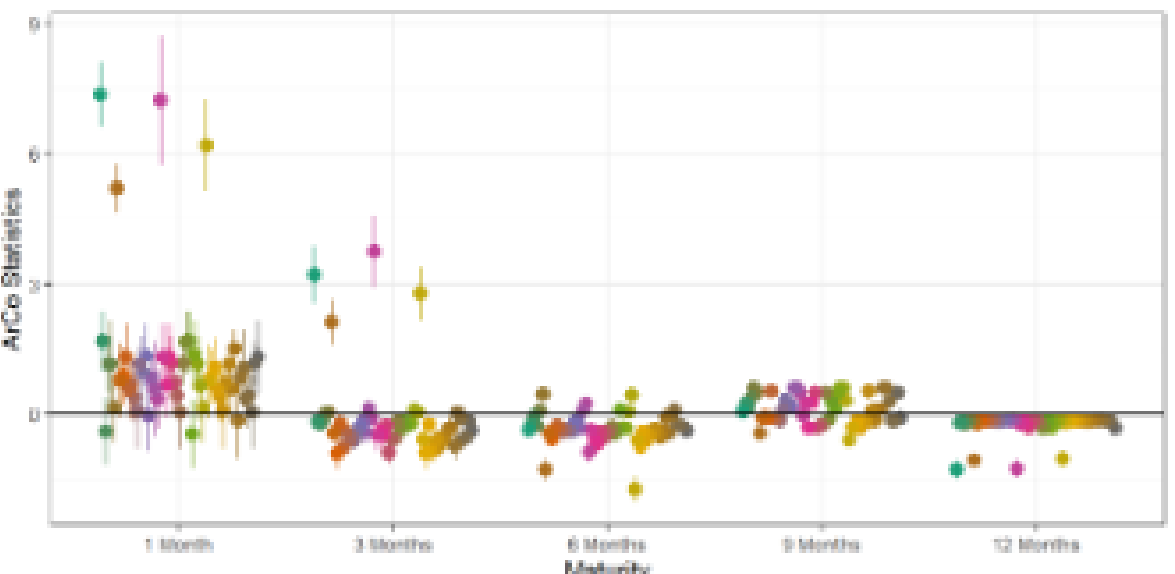

The colors represent an ArCo specification, as exposed in Table B.1. Each graphic represent a specific Sample division, as shown in Figure 3.1. The points represent the ArCo statistic, and the bars represent the $95 \%$ confidence interval. Looking at the Forward Premium models, a negative statistic imply that the observed FP is lower then the estimated counterfactual, which in turn implies in a lower CIP deviation in the absence of intervention. 


\subsection{3}

\section{Local Projections}

The main result of LP estimation is the fact that forward interventions seem to affect the CIP deviations. Spot interventions, on the other hand, seem to have a limited impact on the deviations. Repo sales seem to impact the deviations negatively, and the effect is more significant on the shorter maturity. Furthermore, the analysis among the maturities endorses the ArCo results: the 12-month maturity is the most affected by swap interventions.

Figure 4.4: Swap Interventions Effect on CIP Deviations

(a) Swap - 1 Month CIP Dev.

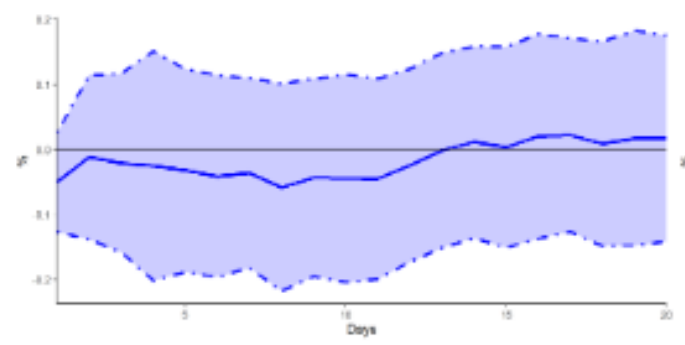

(c) Reverse Swap - 1 Month CIP Dev.

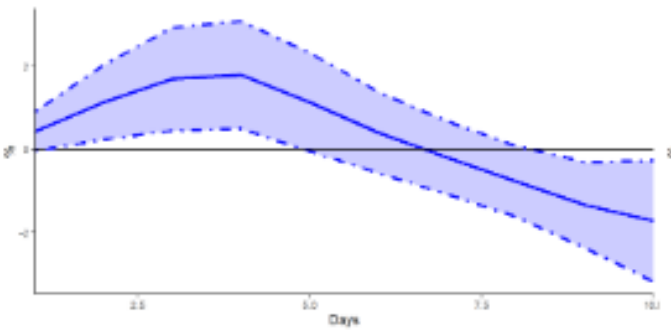

(b) Swap - 12 Month CIP Dev.

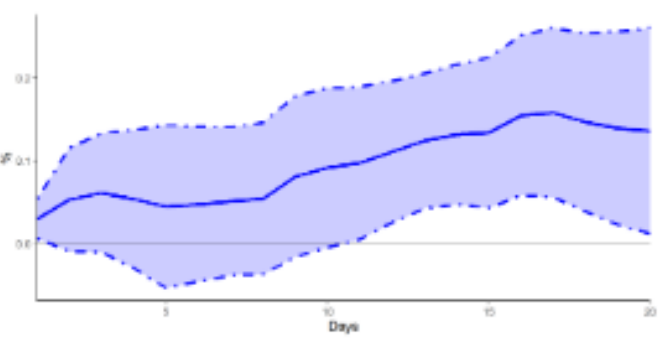

(d) Reverse Swap - 12 Month CIP Dev.

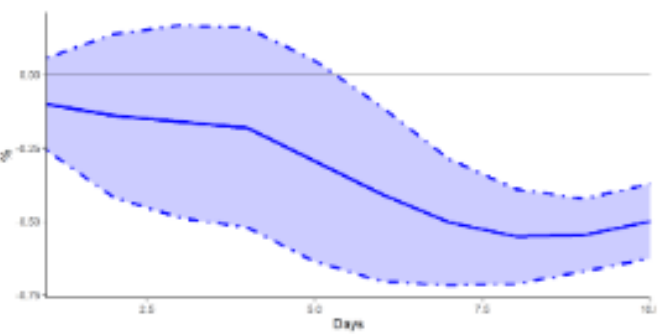

The regressions follow Equation 2-9. The CIP deviations are controlled by the log difference of 5-year Brazilian CDS, VIX and for the spread of bid-and-ask USDBRL in the spot market. We use 5 days lag in both endogenous and exogenous variables. The light blue line represents the $95 \%$ CI, calculated using Newey and West (1987).

Figure 4.4 still points to a negative impact of reverse swap on CIP deviations, indicating somewhat symmetry between the long and short BCB position in this kind of instrument. The IRF's plotted in Figure 4.4 contemplate those reverse swap operations ruled occurred in 2016.

The main drawback faced when examining the intervention observations is the fact the there is no much variation on the major swap program. However, we believe this fact plays in our favor since it implies larger estimated confidence intervals.

Since the onset of the Covid-19 and the social measures adopted for most countries to fight against the virus, there is an ongoing effort by economists to understand and measure the pandemic effects in the economy. Following this 
effort, we add to our sample the recent interventions ruled by the BCB, until 9 April 2020.

The main issue in analyzing this recent data is the small number of observations. The BCB first intervened on 13 Feb. Until 9 Apr, only 11 interventions via swap has occurred, despite the relevant amount of USD 10.5 bn. Then we had to shrink the horizon for 5 days and the lag for one day. We expect to follow the next interventions to evaluate the ongoing impact more precisely. The details of intervention data can be found in Table 3.2. The results we have so far are shown in Figure 4.5.

Figure 4.5: Swap Interventions Effect on CIP Deviations - Covid-19

(a) Swap - 1 Month CIP Dev.

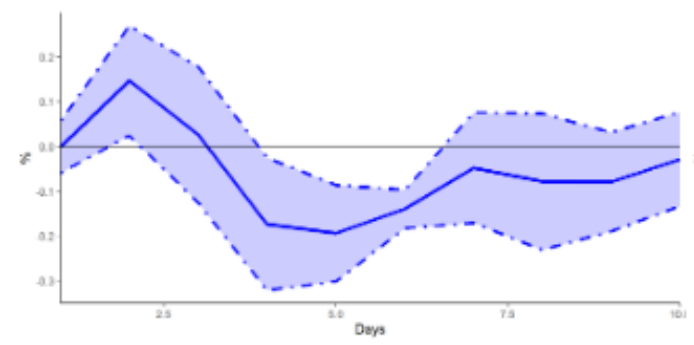

(b) Swap - 12 Month CIP Dev.

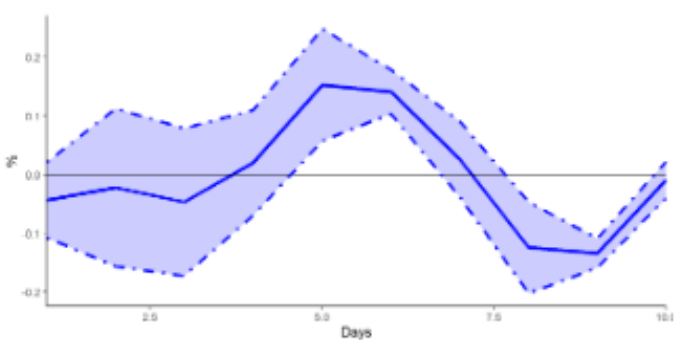

The regressions follow Equation 2-9. The CIP deviations are controlled by the log difference of 5-year Brazilian CDS, VIX and for the spread of bid-and-ask USDBRL in the spot market. We use 5 days lag in both endogenous and exogenous variables. The light blue line represents the $95 \%$ CI, calculated using Newey and West (1987).

For both purchase and sales, CIP response to a spot intervention is more irregular and not statistically different from zero, for most horizons. This result maintains for every maturity of parity we have studied, as shown in Figure 4.6. Although this result guard similarities with Walker (2019), who suggests that any pressure put on the spot quotations are transmitted to the forward prices equivalently, we observe this result cautiously. No major program of preannounced spot interventions was indeed ruled in our sample, but differently from repo and swap interventions, the $\mathrm{BCB}$ action regarding purchase and sales of spot currency is clustered, as can be seen in Figure 3.2.

Despite any announcement, the purchases of spot currency from 2009 and 2012 were ruled almost daily. At that time, the BCB used the massive inflow of capital, because of Taper Tantrum, to increase Brazilian international reserve. The same is true for spot sales interventions in $2 \mathrm{H} 19$. At that time, the BCB aimed to settled some open swap contracts by switching for spot currency, as explained next. In both periods, despite any announcement, the pattern might be observed by the players, in the sense that these interventions have little or no surprise effect and the impact on the CIP deviations was accumulated 
throughout the whole period. The IRF's for spot interventions can be seen in Figure 4.6 below.

Figure 4.6: Spot Interventions Effect on CIP Deviations

(a) Spot Purchase - 1 Month CIP Dev.

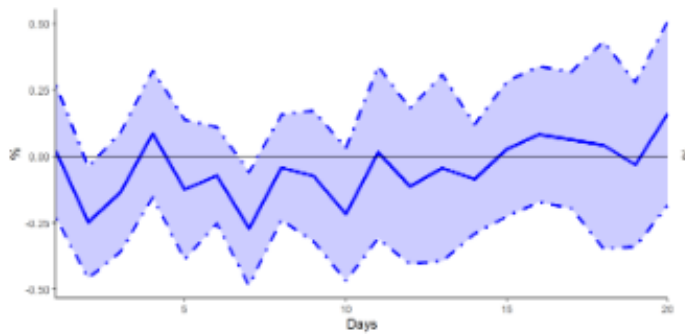

(c) Spot Sale - 1 Month CIP Dev.

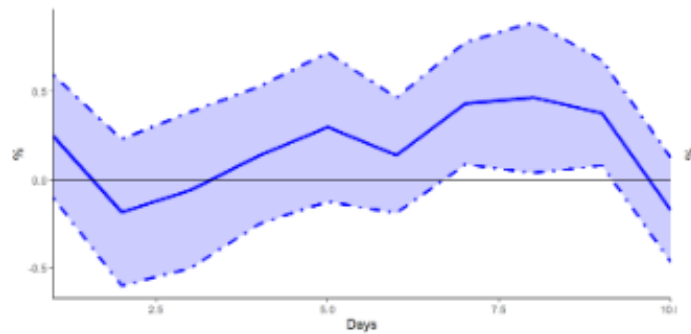

(b) Spot Purchase - 12 Months CIP Dev.

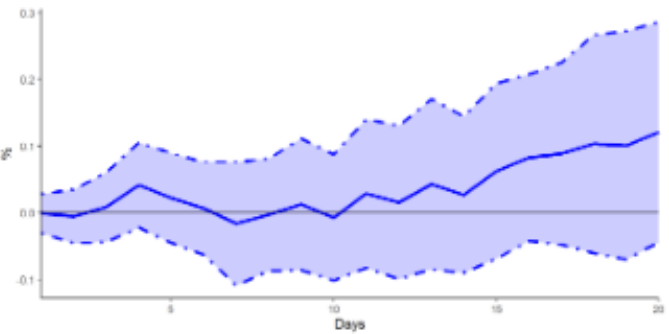

(d) Spot Sale - 12 Months CIP Dev.

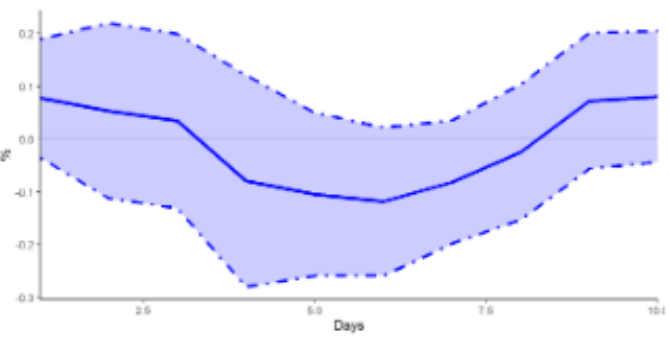

The regressions follow Equation 2-9. The CIP deviations are controlled by the log difference of 5-year Brazilian CDS, VIX and for the spread of bid-and-ask USDBRL in the spot market. We use 5 days lag in both endogenous and exogenous variables. The light blue line represents the $95 \%$ CI, calculated using Newey and West (1987).

As mentioned, we deserve a special discussion for the concomitant interventions of Reverse Swap and Spot Sales ruled in the second half of 2019. The Central Bank liquidated open swap contracts through reverse swap operations, by simultaneously selling spot currency. This operation aimed to re-balance the swap contracts portfolio and the liquidity in the spot market. Then it not represented an FXI as usual. Figure B.9 illustrate the IRF's for these interventions. The dynamic is completely different from those reverse swap operations ruled in 2016. The concomitant spot sales seem to offset any deviation if not increasing, which seems to happen in the 1-month deviation. The spot purchase IRF's are those shown in Figure 4.6. Then, there are reasons to believe that the lack of effect on the CIP deviations could be driven by this special intervention pattern.

Differently from the previous years, the Central Bank has used both swap and spot sales in the Covid-19 crisis. However, a trade-off emerges in the spot analysis, since the number of observation is even smaller than the swap interventions - only 6 days, summing USD 24.5 bn - and merging with the 2019 data, the number of missing values strongly increases. We expect to collect more data in the next months to correctly evaluate this impact. 
Figure 4.7: Reverse Swap Effect on CIP Deviations - 2H2019

(a) Reverse Swap - 1 Month CIP Dev.

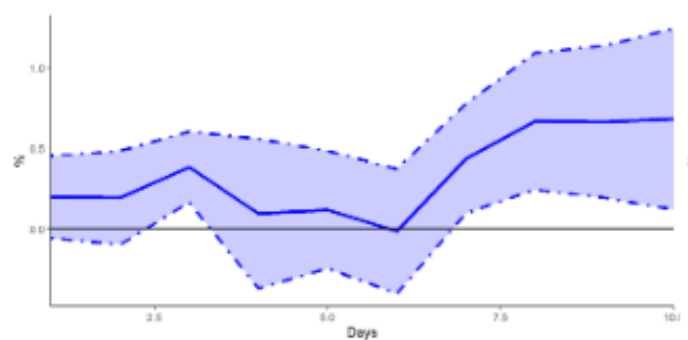

(b) Reverse Swap - 12 Months CIP Dev.

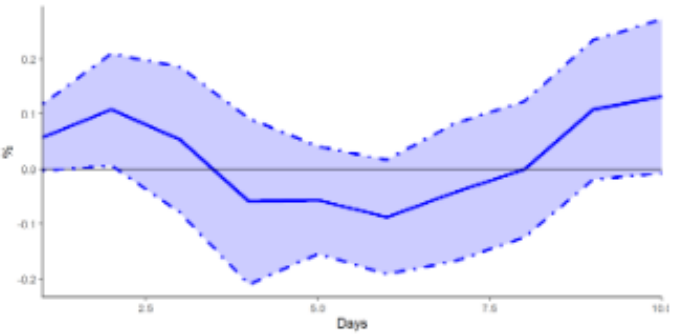

The regressions follow Equation 2-9. The CIP deviations are controlled by the log difference of 5-year Brazilian CDS, VIX and for the spread of bid-and-ask USDBRL in the spot market. We use 5 days lag in both endogenous and exogenous variables. The light blue line represents the 95\% CI, calculated using Newey and West (1987).

Figure 4.8: Repo Interventions Effect on CIP Deviations

(a) Repo Purchase - 1 Month CIP Dev.

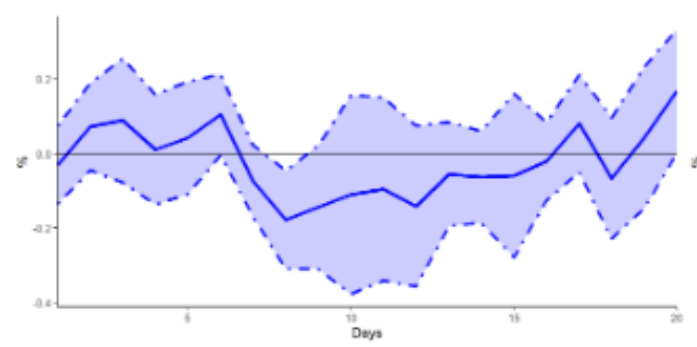

(c) Repo Sale - 1 Month CIP Dev.

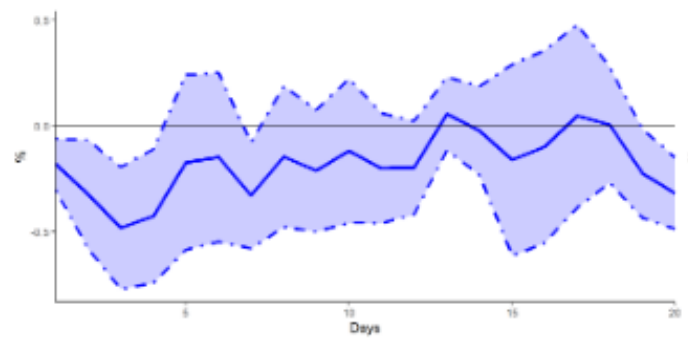

(b) Repo Purchase - 12 Months CIP Dev.

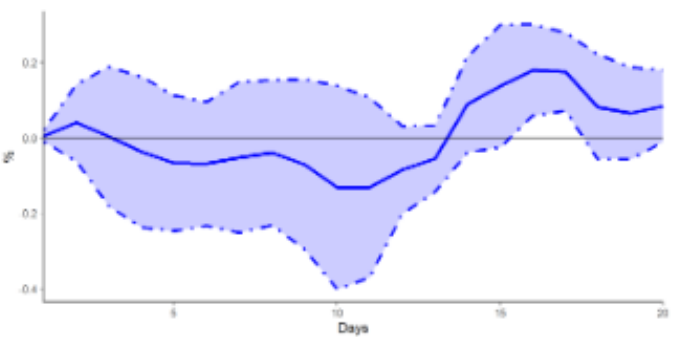

(d) Repo Sale - 12 Months CIP Dev.

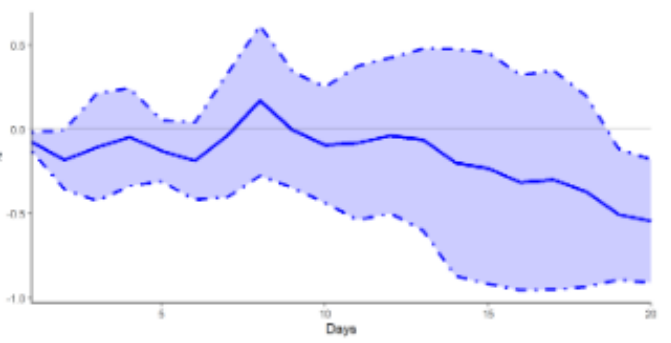

The regressions follow Equation 2-9. The CIP deviations are controlled by the log difference of 5-year Brazilian CDS, VIX and for the spread of bid-and-ask USDBRL in the spot market. We use 5 days lag in both endogenous and exogenous variables. The light blue line represents the 95\% CI, calculated using Newey and West (1987).

As mentioned earlier, the repo lines interventions had a special place on the 2013 major swap program. This line of credit is offered when the BCB observes some lack of liquidity in the spot market. In the 2013 program context, it was designed to correct some eventual liquidity dysfunctionality on the spot market caused by the forward interventions. Then, one interpretation of the inverse pattern we observe in Figure 4.8 might be agents adjusting their 
positions using the new credit lines, which closes the gap between forward premium and the interest rate differential.

Finally, the same IRF's shown here for the maturities of 3, 6, and 9 months were left in Appendix B. 


\section{5}

\section{Conclusion}

Covered interest parity (CIP) has been violated in emerging markets for a long time. For this reason, the absence of deviations to CIP was used as a measure of perfect capital mobility. The 2008 GFC, and the tougher financial regulations that it entailed, generated deviations even in derivatives markets of advanced economies currencies, as documented by Du et al. (2018) and Avdjiev et al. (2019) among others. Here, we contribute to this literature by analyzing the effects of FX interventions on the CIP deviations.

Using the major intervention program ruled by the BCB, we find that daily forward interventions have increased the deviations in 35 bps in the 12-month maturity, on average. The deviation increases along the maturity monetary authority are issuing the contracts.

Local Projection shows a small contemporaneous effect which, however, remains along the time. This effect is also higher for longer maturities, the same pattern demonstrated in ArCo. Moreover, reverse swaps produce the opposite effect, evidencing symmetry between these operations.

Still, local projection indicated that spot interventions have a limited impact on the deviations. We observe this result cautiously since both spot purchase and sale in our sample were ruled in specific conditions, which might affect the measure of this effect. Repo lines, on the other hand, seem to have the opposite impact of swap interventions. One possible explanation for this result is the fact that this repurchase agreement corrects some liquidity issues on the spot market, adjusting the prices toward the parity.

There is some difficulty involved in linking the Local Projection's impulse response functions results with ArCo due to the methodologies' different approaches, despite the fact they point to the same directions. However, we think the IRF sheds light on the dynamic of the interventions by indicating small contemporaneous results which, however, remains in the middle term.

We believe our work contributes to FXI and CIP deviations literature and left open some channels for further research on the interaction between them. 


\section{Bibliography}

Abadie, A., Diamond, A., and Hainmueller, J. (2010). Synthetic control methods for comparative case studies: Estimating the effect of california's tobacco control program. Journal of the American statistical Association, 105(490):493-505.

Adämmer, P. (2019). Ipirfs: An r package to estimate impulse response functions by local projections. Ipirfs: An R Package to Estimate Impulse Response Functions by Local Projections. The R Journal. Forthcoming.

Amador, M., Bianchi, J., Bocola, L., and Perri, F. (2019). Exchange rate policies at the zero lower bound. Review of Economic Studies. Forthcoming.

Avdjiev, S., Du, W., Koch, C., and Shin, H. S. (2019). The dollar, bank leverage, and deviations from covered interest parity. American Economic Review: Insights, 1(2):193-208.

Blanchard, O., Adler, G., and Carvalho Filho, I. (2015). Can foreign exchange intervention stem exchange rate pressures from global capital flow shocks? Technical report, National Bureau of Economic Research.

Carvalho, C., Masini, R., and Medeiros, M. C. (2018). Arco: An artificial counterfactual approach for high-dimensional panel time-series data. Journal of Econometrics, 207(2):352-380.

Cerutti, E. M., Obstfeld, M., and Zhou, H. (2019). Covered interest parity deviations: Macrofinancial determinants. National Bureau of Economic Research.

Chamon, M., Garcia, M., and Souza, L. (2017). Fx interventions in brazil: A synthetic control approach. Journal of International Economics, 108:157-168.

Cieplinski, A., Braga, J., and Summa, R. (2014). Avaliação empírica do teorema da paridade coberta para a economia brasileira. Texto para Discussão, 22.

Craveiro, V. A. M. (2019). Efeito das intervenções do banco central do brasil na curva de cupom cambial. MSc Dissertation in Macroeconomics and Finance Department of Economics, PUC-Rio.

Domanski, D., Kohlscheen, E., and Moreno, R. (2016). Foreign exchange market intervention in emerging market economies: what has changed? BIS Quarterly Review September. 
Dominguez, K. M. E. (2019). Emerging market exchange rate policies: Stabilizing or manipulation? IMF-CBC-IMFER Conference, Santiago, Chile.

Du, W., Tepper, A., and Verdelhan, A. (2018). Deviations from covered interest rate parity. The Journal of Finance, 73(3):915-957.

Eichengreen, B. and Gupta, P. (2015). Tapering talk: The impact of expectations of reduced federal reserve security purchases on emerging markets. Emerging Markets Review, 25:1-15.

Engel, C., Lee, D., Liu, C., Liu, C., and Wu, S. P. Y. (2019). The uncovered interest parity puzzle, exchange rate forecasting, and taylor rules. Journal of International Money and Finance, 95:317-331.

Fama, E. F. (1984). Forward and spot exchange rates. Journal of monetary economics, 14(3):319-338.

Fonseca, Y. R., Masini, R. P., Medeiros, M. C., and Vasconcelos, G. F. (2017). ArCo: Artificial Counterfactual Package. R package version 0.3-1.

Fonseca, Y. R., Masini, R. P., Medeiros, M. C., and Vasconcelos, G. F. (2018). Arco: A $r$ package to estimate artificial counterfactuals. The $R$ Journal, 10(1):91-108.

Garcia, M. and Volpon, T. (2014). Dndfs: a more efficient way to intervene in $\mathrm{fx}$ markets? Texto para discussão No. 621.

Garcia, M. G. and Didier, T. (2003). Taxa de juros, risco cambial e risco brasil. Instituto de Pesquisa Econômica Aplicada (Ipea) - Pesquisa e Plânejamento Econômico, 33(2).

Gonzalez, R., Khametshin, D., Peydró, J.-L., and Polo, A. (2019). Hedger of last resort: evidence from brazilian $\mathrm{fx}$ interventions, local credit and global financial cycles. Economic Working Paper Series Working Paper No. 1648.

Hofmann, B., Shin, H. S., and Villamizar-Villegas, M. (2019). Fx intervention and domestic credit: evidence from high-frequency micro data. BIS working paper.

Jordà, Ò. (2005). Estimation and inference of impulse responses by local projections. American economic review, 95(1):161-182.

Kohlscheen, E. and Andrade, S. C. (2014). Official fx interventions through derivatives. Journal of International Money and Finance, 47:202-216.

Menkhoff, L. (2013). Foreign exchange intervention in emerging markets: A survey of empirical studies. The World Economy, 36(9):1187-1208. 
Nedeljkovic, M. and Saborowski, C. (2019). The relative effectiveness of spot and derivatives-based intervention. Journal of Money, Credit and Banking, 51(6):1455-1490.

Newey, W. K. and West, K. D. (1987). Hypothesis testing with efficient method of moments estimation. International Economic Review, pages 777-787.

Oliveira, F. N. (2020). Empirical analyses of the effectiveness of interventions in the foreign exchange market in brazil. Revista Brasileira de Finanças, 18(2).

Plagborg-Møller, M. and Wolf, C. K. (2019). Local projections and vars estimate the same impulse responses. Unpublished paper: Department of Economics, Princeton University, page 1.

Ramey, V. A. and Zubairy, S. (2018). Government spending multipliers in good times and in bad: evidence from us historical data. Journal of Political Economy, 126(2):850-901.

Romer, C. D. and Romer, D. H. (2010). The macroeconomic effects of tax changes: estimates based on a new measure of fiscal shocks. American Economic Review, 100(3):763-801.

Sarno, L. and Taylor, M. P. (2001). Official intervention in the foreign exchange market: is it effective and, if so, how does it work? Journal of Economic Literature, 39(3):839-868.

Stock, J. H. and Watson, M. W. (2018). Identification and estimation of dynamic causal effects in macroeconomics using external instruments. The Economic Journal, 128(610):917-948.

Vasconcelos, G. F. (2017). HDeconometrics: Implementation of several econometric models in high-dimension. $\mathrm{R}$ package version 1.0 .

Ventura, A. and Garcia, M. (2012). Mercados futuro e à vista de câmbio no brasil: o rabo abana o cachorro. Revista Brasileira de Economia, 66(1):21-48.

Walker, C. (2019). Forward intervention. Foreign Exchange Intervention in Inflation Targeters in Latin America. 


\section{A}

\section{Data Appendix}

The following data are collected from Thomson Reuters Datastream platform.

Exchange Rates. We use the Thomson Reuters as the source for the Australian dollar, Brazilian real, Canadian dollar, Czech koruna, Euro, Hungarian forint, Indian rupee, Israeli shekel, Japanese yen, Mexican peso, Philippine peso, South Korean won, and New Turkish lira. For the Chilean peso, we use WM/Reuters as the source, the same for their NDF.

Interest Rates. All data are collected from the Thomson Reuters Datastream platform. The tickers of the respective variables are in parenthesis.

We use the USD LIBOR as the foreign interest rate when calculating the CIP. For the domestic interest rates, we use the Australian dollar deposit, Brazil DI-Pré fixed float, Canadian interbank offered rate (CIDOR), Chilean interbank, Czech Republic interbank, Euribor, Hungary interbank, India deposit rate, Tel Aviv interbank, Japan interbank (TIBOR), Mexico CETES, Philippine interbank call loan rate and Philippine treasury bill, South Korea interbank and Turkey interbank.

When a particular maturity is not directly observed, we estimated via linear interpolation. This is the case for the Japan interbank (TIBOR) for 3 months, and for the Canadian interbank (CIDOR), Chilean interbank, TIBOR, Mexicos CETES and Philippine treasury bill for 9 months.

Equity Indices. S\&P/ASX 200 (Australia), Bovespa (Brazil), S\&P/TSX Composite Index (Canada), S\&P/CLX IGPA CLP Index (Chile), Prague SE PX (Czech Republic), S\&P Europe 350 (Euro), Budapest-BUX (Hungary), S\&P BSE (SENSEX) 30 Sensitive (India), TA 125 (Israel), Nikkei 225 Stock Average (Japan), IPC (Mexico), SE I(PSEi) (Philippine), SE CompositeKOSPI (Korea) and BIST National 100 (Turkey).

Credit Default Swap. For most countries, we use sovereign 5-year CDS. We choose this maturity due to its liquidity. The exceptions are for Eurozone, which we use the 5-year Germany CDS, and for India, where the 5 year CDS series starts only in March/2015 and we use the 5-year CDS of the Bank of India, a state-owned bank, as a proxy. 
B

\section{Results Appendix}

Table B.1: List of the Models - Daily Data

\begin{tabular}{|c|c|c|}
\hline \multicolumn{3}{|c|}{ Covered Interest Parity } \\
\hline $\operatorname{ArCo} 1$ & & CIP \\
\hline ArCo 2 & & CIP + Equities Indices \\
\hline $\mathrm{ArCo} 3$ & & $\mathrm{CIP}+\mathrm{CDS}$ \\
\hline $\mathrm{ArCo}_{4}$ & & CIP + Bid and Ask Spread \\
\hline $\mathrm{ArCo} 5$ & No Exogenous Control & CIP + Equities Indices + CDS \\
\hline $\operatorname{ArCo} 6$ & & $\mathrm{CIP}+$ Equities Indices + CDS + Bid and Ask Spread \\
\hline $\operatorname{ArCo} 7$ & & CIP + Equities Indices + Bid and Ask Spread \\
\hline $\operatorname{ArCo} 8$ & & CIP + CDS + Bid and Ask Spread \\
\hline ArCo 9 & & CIP \\
\hline ArCo 10 & & CIP + Equities Indices \\
\hline ArCo 11 & & $\mathrm{CIP}+\mathrm{CDS}$ \\
\hline ArCo 12 & & CIP + Bid and Ask Spread \\
\hline ArCo 13 & USD Index & CIP + Equities Indices + CDS \\
\hline ArCo 14 & & CIP + Equities Indices + CDS + Bid and Ask Spread \\
\hline ArCo 15 & & CIP + Equities Indices + Bid and Ask Spread \\
\hline ArCo 16 & & CIP + CDS + Bid and Ask Spread \\
\hline ArCo 17 & & CIP \\
\hline ArCo 18 & & CIP + Equities Indices \\
\hline ArCo 19 & & $\mathrm{CIP}+\mathrm{CDS}$ \\
\hline ArCo 20 & & CIP + Bid and Ask Spread \\
\hline ArCo 21 & VIX & $\mathrm{CIP}+$ Equities Indices + CDS \\
\hline ArCo 22 & & CIP + Equities Indices + CDS + Bid and Ask Spread \\
\hline ArCo 23 & & CIP + Equities Indices + Bid and Ask Spread \\
\hline ArCo 24 & & CIP + CDS + Bid and Ask Spread \\
\hline ArCo 25 & & CIP \\
\hline ArCo 26 & & CIP + Equities Indices \\
\hline ArCo 27 & & $\mathrm{CIP}+\mathrm{CDS}$ \\
\hline ArCo 28 & & CIP + Bid and Ask Spread \\
\hline ArCo 29 & USD Index + VIX & CIP + Equities Indices + CDS \\
\hline ArCo 30 & & $\mathrm{CIP}+$ Equities Indices + CDS + Bid and Ask Spread \\
\hline ArCo 31 & & CIP + Equities Indices + Bid and Ask Spread \\
\hline ArCo 32 & & CIP + CDS + Bid and Ask Spread \\
\hline
\end{tabular}

\begin{tabular}{|c|c|c|}
\hline \multicolumn{3}{|c|}{ Forward Premium } \\
\hline $\mathrm{ArCo} 1$ & \multirow{8}{*}{ IRD } & \\
\hline $\mathrm{ArCo} 2$ & & FP + Equities Indices \\
\hline $\mathrm{ArCo} 3$ & & $\mathrm{FP}+\mathrm{CDS}$ \\
\hline $\mathrm{ArCo} 4$ & & FP + Bid and Ask Spread \\
\hline $\mathrm{ArCo} 5$ & & FP + Equities Indices + CDS \\
\hline $\mathrm{ArCo} 6$ & & FP + Equities Indices + CDS + Bid and Ask Spread \\
\hline $\mathrm{ArCo} 7$ & & FP + Equities Indices + Bid and Ask Spread \\
\hline $\operatorname{ArCo} 8$ & & FP + CDS + Bid and Ask Spread \\
\hline $\mathrm{ArCo} 9$ & \multirow{8}{*}{ IRD + USD Index } & \\
\hline ArCo 10 & & FP + Equities Indices \\
\hline ArCo 11 & & $\mathrm{FP}+\mathrm{CDS}$ \\
\hline $\mathrm{ArCo} 12$ & & FP + Bid and Ask Spread \\
\hline ArCo 13 & & FP + Equities Indices + CDS \\
\hline $\mathrm{ArCo} 14$ & & FP + Equities Indices + CDS + Bid and Ask Spread \\
\hline ArCo 15 & & FP + Equities Indices + Bid and Ask Spread \\
\hline ArCo 16 & & FP + CDS + Bid and Ask Spread \\
\hline $\mathrm{ArCo} 17$ & \multirow{8}{*}{ IRD + VIX } & \\
\hline ArCo 18 & & $\mathrm{FP}+$ Equities Indices \\
\hline ArCo 19 & & $\mathrm{FP}+\mathrm{CDS}$ \\
\hline ArCo 20 & & FP + Bid and Ask Spread \\
\hline $\mathrm{ArCo} 21$ & & $\mathrm{FP}+$ Equities Indices + CDS \\
\hline ArCo 22 & & FP + Equities Indices + CDS + Bid and Ask Spread \\
\hline ArCo 23 & & FP + Equities Indices + Bid and Ask Spread \\
\hline ArCo 24 & & FP + CDS + Bid and Ask Spread \\
\hline $\mathrm{ArCo} 25$ & \multirow{8}{*}{ IRD + USD Index + VIX } & FP \\
\hline ArCo 26 & & $\mathrm{FP}+$ Equities Indices \\
\hline ArCo 27 & & $\mathrm{FP}+\mathrm{CDS}$ \\
\hline $\mathrm{ArCo} 28$ & & FP + Bid and Ask Spread \\
\hline ArCo 29 & & $\mathrm{FP}+$ Equities Indices + CDS \\
\hline $\mathrm{ArCo} 30$ & & FP + Equities Indices + CDS + Bid and Ask Spread \\
\hline ArCo 31 & & FP + Equities Indices + Bid and Ask Spread \\
\hline $\mathrm{ArCo} 32$ & & FP + CDS + Bid and Ask Spread \\
\hline
\end{tabular}

List of abbreviations: Covered Interest Parity (CIP), Forward Premium (FP), 5-year Credit Default Swap (CDS). "Equities Indices" represent the stock market index of each country. "Bid and Ask Spread" represent the log difference between the bid and ask spot dollar, for each currency. USD Index is the Trade Weighted U.S. Dollar Index, elaborated by the Board of Governors of the Federal Reserve System (US). VIX is the CBOE Volatility Index, elaborated by the Chicago Board Options Exchange. Excepting the CIP, FP and IRD, all other variables are estimated by the log differential. 
Table B.2: List of the Models - Weekly Data

\begin{tabular}{|c|c|c|}
\hline & & overed Interest Parity \\
\hline & & CIP \\
\hline & & $\begin{array}{l}\text { CIP + Equities Indices } \\
\text { CIP + CDS }\end{array}$ \\
\hline $\mathrm{ArCo} 4$ & & CIP + Bid and Ask Spread \\
\hline $\operatorname{ArCo} 5$ & & CIP + Equities Indices + CDS \\
\hline ArCo 6 & & CIP + Equities Indices + CDS + Bid and Ask Spread \\
\hline $\mathrm{ArCo} 7$ & No Exogenous Control & CIP + Equities Indices + Bid and Ask Spread \\
\hline $\mathrm{ArCo} 8$ & & CIP + CDS + Bid and Ask Spread \\
\hline $\begin{array}{l}\mathrm{ArCo} 9 \\
\mathrm{ArCo} 10\end{array}$ & & CIP + Equity Flow \\
\hline $\begin{array}{l}\text { ArCo } 10 \\
\text { ArCo } 11\end{array}$ & & CIP + Bond Flow \\
\hline $\begin{array}{l}\mathrm{ArCo} 11 \\
\mathrm{ArCo} 12\end{array}$ & & CIP + Equity Flow + Bond Flow + Equities Indices \\
\hline $\begin{array}{cl}\mathrm{ArCO} & 12 \\
\mathrm{ArCo} & 13\end{array}$ & & CIP + Equity Flow + Bond Flow + CDS \\
\hline $\begin{array}{l}\mathrm{ArCo} 13 \\
\mathrm{ArCo} 14\end{array}$ & & \begin{tabular}{|l} 
CIP + Equity Flow + Bond Flow + Bid and Ask Spread \\
CIP + Eq Flow + Bond Flow + CDS + EI + BA pread
\end{tabular} \\
\hline ArCo 15 & & \\
\hline ArCo 16 & & CIP + Equities Indices \\
\hline $\mathrm{ArCo} 17$ & & $\mathrm{CIP}+\mathrm{CDS}$ \\
\hline ArCo 18 & & CIP + Bid and Ask Spread \\
\hline ArCo 19 & & CIP + Equities Indices + CDS \\
\hline ArCo 20 & & CIP + Equities Indices + CDS + Bid and Ask Spread \\
\hline $\mathrm{ArCo} 21$ & & CIP + Equities Indices + Bid and Ask Spread \\
\hline ArCo 22 & USD Index & CIP + CDS + Bid and Ask Spread \\
\hline $\mathrm{ArCo} 23$ & & CIP + Equity Flow \\
\hline $\mathrm{ArCo} 24$ & & CIP + Bond Flow \\
\hline ArCo 25 & & CIP + Equity Flow + Bond Flow + Equities Indices \\
\hline $\mathrm{ArCo} 26$ & & CIP + Equity Flow + Bond Flow + CDS \\
\hline ArCo 27 & & CIP + Equity Flow + Bond Flow + Bid and Ask Spread \\
\hline ArCo 28 & & CIP + Eq. Flow + Bond Flow + CDS + EI + BA Spread \\
\hline ArCo 29 & & \\
\hline ArCo 30 & & CIP + Equities Indices \\
\hline $\mathrm{ArCo} 31$ & & 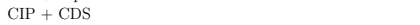 \\
\hline $\mathrm{ArCo} 32$ & & CIP + Bid and Ask Spread \\
\hline ArCo 33 & & CIP + Equities Indices + CDS \\
\hline $\mathrm{ArCo} 34$ & & CIP + Equities Indices + CDS + Bid and Ask Spread \\
\hline $\mathrm{ArCo} 35$ & VIX & CIP + Equities Indices + Bid and Ask Spread \\
\hline ArCo 36 & & CIP + CDS + Bid and Ask Spread \\
\hline $\mathrm{ArCo} 37$ & & CIP + Equity Flow \\
\hline $\mathrm{ArCo} 38$ & & CIP + Bond Flow \\
\hline ArCo 39 & & CIP + Equity Flow + Bond Flow + Equities Indices \\
\hline $\mathrm{ArCo} 40$ & & CIP + Equity Flow + Bond Flow + CDS \\
\hline $\mathrm{ArCo} 41$ & & CIP + Equity Flow + Bond Flow + Bid and Ask Spread \\
\hline $\mathrm{ArCo} 42$ & & CIP + Eq. Flow + Bond Flow + CDS + EI + BA Spread \\
\hline $\mathrm{ArCo} 43$ & & CIP \\
\hline $\mathrm{ArCo} 44$ & & CIP + Equities Indice \\
\hline ArCo 45 & & $\mathrm{CIP}+\mathrm{C}$ \\
\hline ArCo 46 & & CIP + Bid and Ask Spread \\
\hline $\mathrm{ArCo} 47$ & & CIP + Equities Indices + CDS \\
\hline $\mathrm{ArCo} 48$ & & CIP + Equities Indices + CDS + Bid and Ask Spread \\
\hline ArCo 49 & USD Index + VIX & CIP + Equities Indices + Bid and Ask Spread \\
\hline $\begin{array}{rl}\mathrm{ArCo} & 50 \\
\mathrm{ArC0} & 51\end{array}$ & & CIP + CDS + Bid and Ask Spread \\
\hline $\begin{array}{l}\mathrm{ArCo} 51 \\
\mathrm{ArCo} 52\end{array}$ & & $\begin{array}{l}\text { CIP + Equity Flow } \\
\text { CIP + Bond Flow }\end{array}$ \\
\hline $\begin{array}{ll}\text { ArCo } 52 \\
\text { ArCo } 53\end{array}$ & & $\begin{array}{l}\text { CII + Bond Flow } \\
\text { CIP + Equity Flow + Bond Flow + Fquities Indices }\end{array}$ \\
\hline $\begin{array}{l}\mathrm{ArCO} 53 \\
\mathrm{ArCo} 54\end{array}$ & & CIP + Equity Flow + Bond Flow + Equities Indices \\
\hline $\begin{array}{ll}\mathrm{ArC} 054 \\
\mathrm{ArCo} & 55\end{array}$ & & $\begin{array}{l}\text { CIP + Equity Flow }+ \text { Bond Flow }+ \text { CDS } \\
\text { CIP + Equity Flow }+ \text { Bond Flow }+ \text { Bid and Ask }\end{array}$ \\
\hline $\mathrm{ArCo} 56$ & & CIP + Eq. Flow + Bond Flow + CDS + EI + BA Spread \\
\hline
\end{tabular}

\begin{tabular}{|c|c|c|}
\hline & & Forward Premium \\
\hline $\mathrm{ArCo} 1$ & & \\
\hline $\mathrm{ArCo} 2$ & & FP + Equities Indices \\
\hline ArCo 3 & & $\mathrm{FP}+\mathrm{CDS}$ \\
\hline $\mathrm{ArCo} 4$ & & FP + Bid and Ask Spread \\
\hline ArCo 5 & & $\mathrm{FP}+$ Equities Indices + CDS \\
\hline ArCo 6 & & FP + Equities Indices + CDS + Bid and Ask Spread \\
\hline $\mathrm{ArCo} 7$ & & FP + Equities Indices + Bid and Ask Spread \\
\hline $\operatorname{ArCo} 8$ & IRD & FP + CDS + Bid and Ask Spread \\
\hline $\operatorname{ArCo} 9$ & & FP + Equity Flow \\
\hline ArCo 10 & & FP + Bond Flow \\
\hline ArCo 11 & & FP + Equity Flow + Bond Flow + Equities Indices \\
\hline ArCo 12 & & FP + Equity Flow + Bond Flow + CDS \\
\hline ArCo 13 & & FP + Equity Flow + Bond Flow + Bid and Ask Spread \\
\hline $\mathrm{ArCo} 14$ & & FP + Eq. Flow + Bond Flow + CDS + EI + BA Spread \\
\hline ArCo 15 & & \\
\hline ArCo 16 & & FP + Equities Indices \\
\hline ArCo 17 & & $\mathrm{FP}+\mathrm{CDS}$ \\
\hline $\mathrm{ArCo} 18$ & & FP + Bid and Ask Spread \\
\hline ArCo 19 & & $\mathrm{FP}+$ Equities Indices + CDS \\
\hline ArCo 20 & & FP + Equities Indices + CDS + Bid and Ask Spread \\
\hline ArCo 21 & IRD + USD Index & \\
\hline ArCo 22 & & FP + CDS + Bid and Ask Spread \\
\hline ArCo 23 & & FP + Equity Flow \\
\hline ArCo 24 & & FP + Bond Flow \\
\hline ArCo 25 & & FP + Equity Flow + Bond Flow + Equities Indices \\
\hline ArCo 26 & & FP + Equity Flow + Bond Flow + CDS \\
\hline $\mathrm{ArCo} 27$ & & FP + Equity Flow + Bond Flow + Bid and Ask Spread \\
\hline ArCo 28 & & FP + Eq. Flow + Bond Flow + CDS + EI + BA Spread \\
\hline ArCo 29 & & FP \\
\hline ArCo 30 & & FP + Equities Indices \\
\hline $\mathrm{ArCo} 31$ & & $\mathrm{FP}+\mathrm{CDS}$ \\
\hline ArCo 32 & & FP + Bid and Ask Spread \\
\hline ArCo 33 & & FP + Equities Indices + CDS \\
\hline $\mathrm{ArCo} 34$ & & FP + Equities Indices + CDS + Bid and Ask Spread \\
\hline ArCo 35 & IRD + VIX & FP + Equities Indices + Bid and Ask Spread \\
\hline ArCo 36 & & FP + CDS + Bid and Ask Spread \\
\hline $\mathrm{ArCo} 37$ & & FP + Equity Flow \\
\hline ArCo 38 & & FP + Bond Flow \\
\hline ArCo 39 & & FP + Equity Flow + Bond Flow + Equities Indices \\
\hline $\operatorname{ArCo} 40$ & & FP + Equity Flow + Bond Flow + CDS \\
\hline ArCo 41 & & FP + Equity Flow + Bond Flow + Bid and Ask Spread \\
\hline $\mathrm{ArCo} 42$ & & FP + Eq. Flow + Bond Flow + CDS + EI + BA Spread \\
\hline & & \\
\hline & & $\mathrm{FP}+$ Equities Indices \\
\hline $\mathrm{ArCo} 45$ & & $\mathrm{FP}+\mathrm{CDS}$ \\
\hline $\mathrm{ArCo} 46$ & & FP + Bid and Ask Spread \\
\hline $\mathrm{ArCo} 47$ & & FP + Equities Indices + CDS \\
\hline $\mathrm{ArCo} 48$ & & FP + Equities Indices + CDS + Bid and Ask Spread \\
\hline $\mathrm{ArCo} 49$ & & FP + Equities Indices + Bid and Ask Spread \\
\hline $\mathrm{ArCo} 50$ & IRD + USD Index + VIX & FP + CDS + Bid and Ask Spread \\
\hline $\mathrm{ArCo} 51$ & & FP + Equity Flov \\
\hline $\mathrm{ArCo} 52$ & & FP + Bond Flow \\
\hline $\mathrm{ArCo} 53$ & & FP + Equity Flow + Bond Flow + Equities Ir \\
\hline $\mathrm{ArCo} 54$ & & FP + Equity Flow + Bond Flow + CDS \\
\hline $\mathrm{ArCo} 55$ & & FP + Equity Flow + Bond Flow + Bid and Ask Spread \\
\hline ArCo 56 & & FP + Eq. Flow + Bond Flow + CDS + EI + BA Spread \\
\hline
\end{tabular}

List of abbreviations: Covered Interest Parity (CIP), Forward Premium (FP), 5-year Credit Default Swap (CDS). "Equities Indices" represent the stock market index of each country. "Bid and Ask Spread" represent the log difference between the bid and ask spot dollar, for each currency. Equity and Bond Flow represent the Haver Analytics capital flows, in million USD, received by country. USD Index is the Trade Weighted U.S. Dollar Index, elaborated by the Board of Governors of the Federal Reserve System (US). VIX is the CBOE Volatility Index, elaborated by the Chicago Board Options Exchange. Excepting the CIP, FP, IRD, Equity and Bond Flows, all other variables are estimated by the log differential. 
Figure B.1: Results - Daily ArCo - Pre 1

(a) CIP - Sample 2

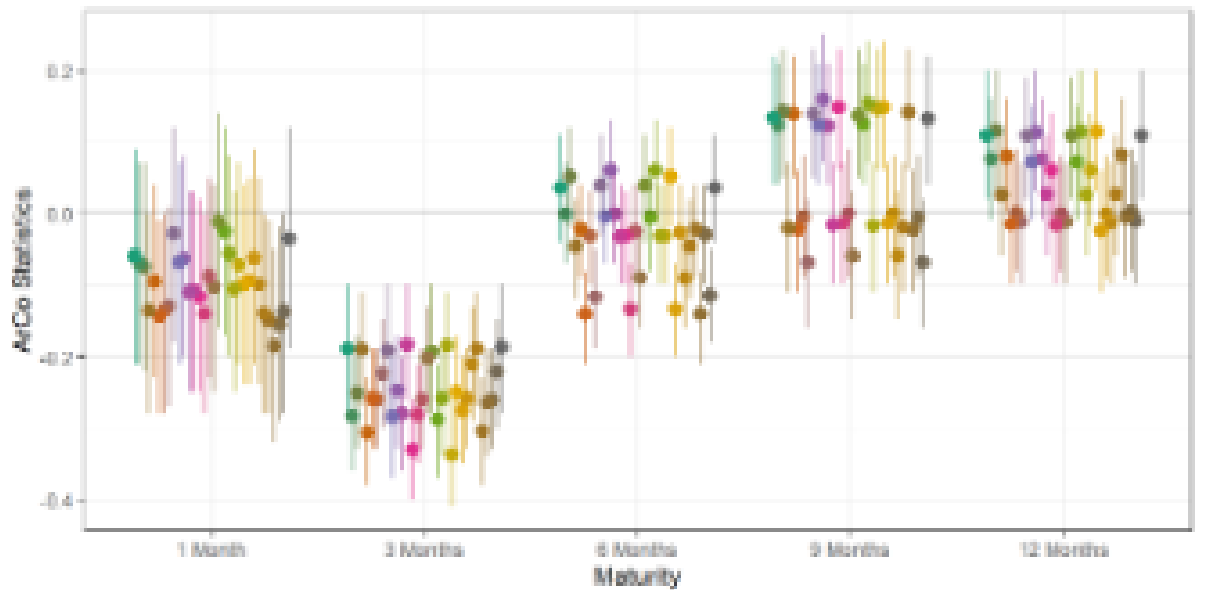

(c) CIP - Sample 4

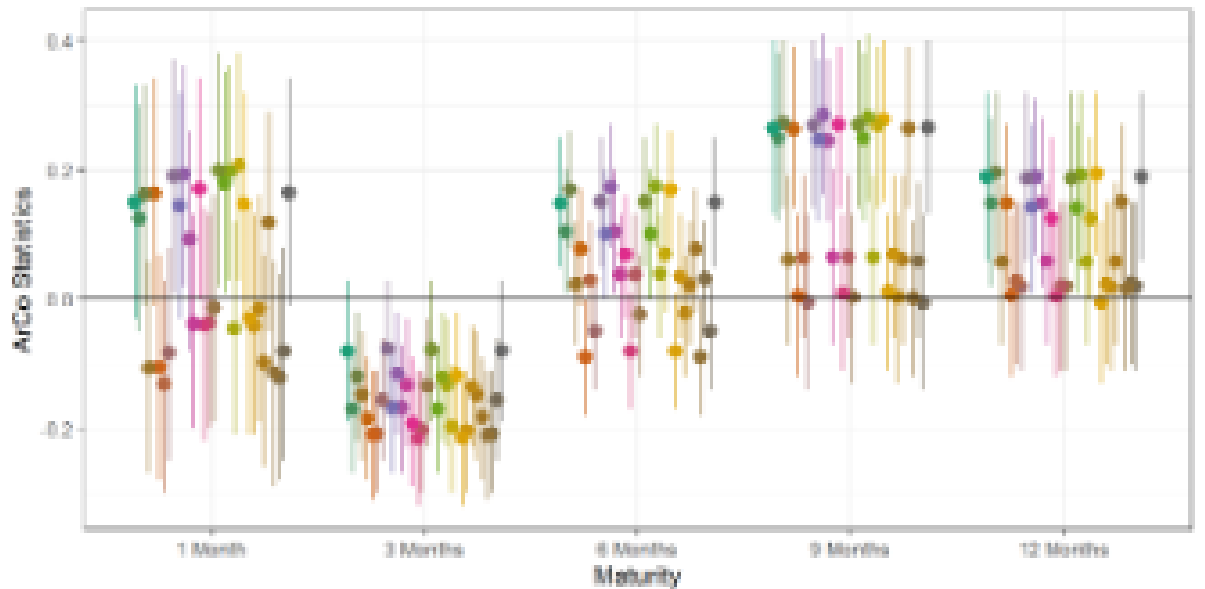

(b) CIP - Sample 3

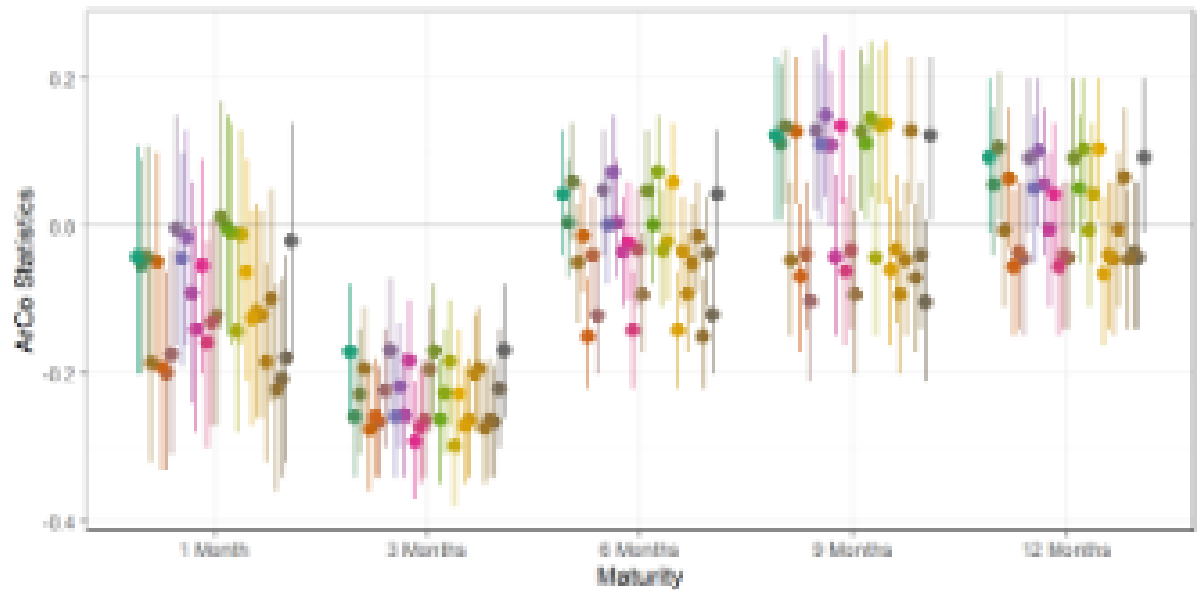

(d) CIP - Sample 5

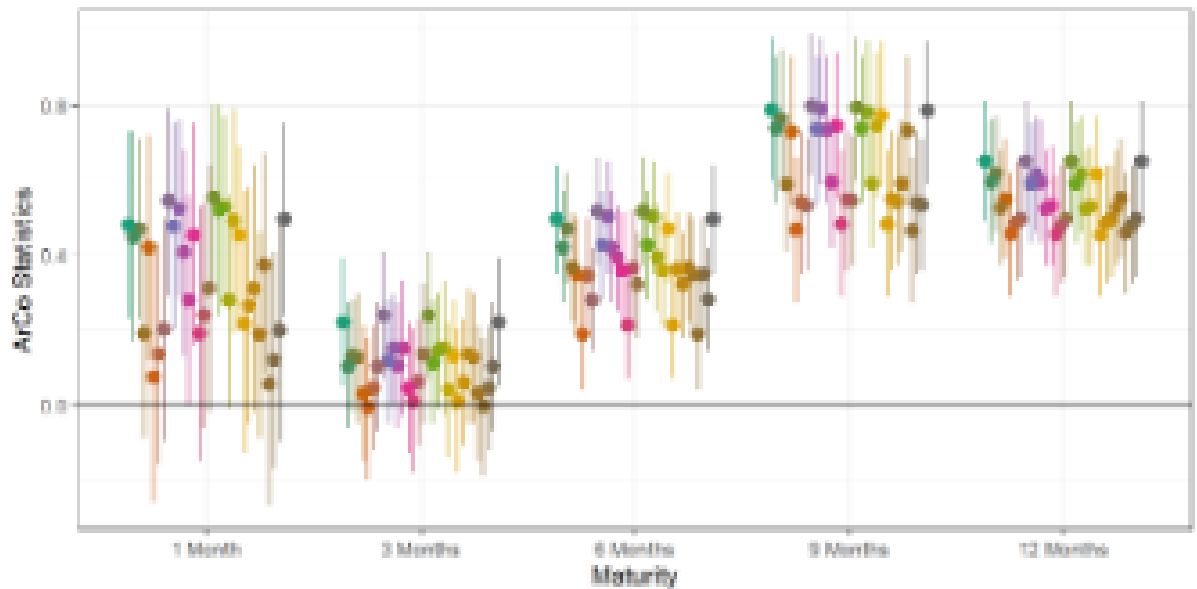

The colors represent an ArCo specification, as exposed in Table B.1. Each graphic represent a specific Sample division, as shown in Figure 3.1. The points represent the ArCo statistic, and the bars represent the 95\% confidence interval. Looking at the Forward Premium models, a negative statistic imply that the observed FP is lower then the estimated counterfactual, which in turn implies in a lower CIP deviation in the absence of intervention. 
Figure B.2: Results - Daily ArCo - Pre 2

(a) CIP - Sample 7

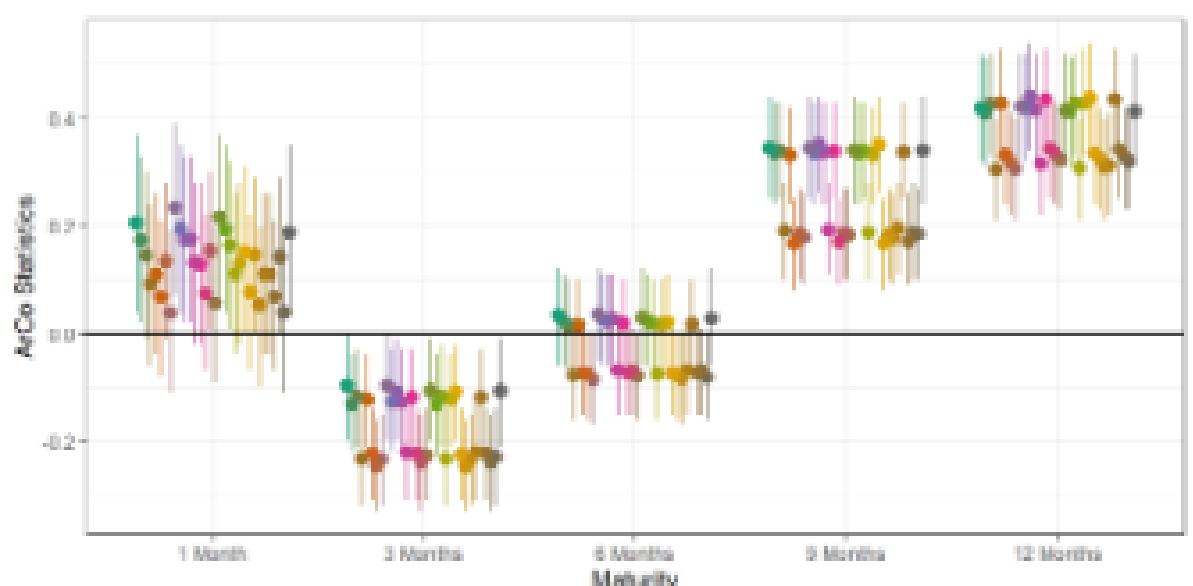

(b) CIP - Sample 8

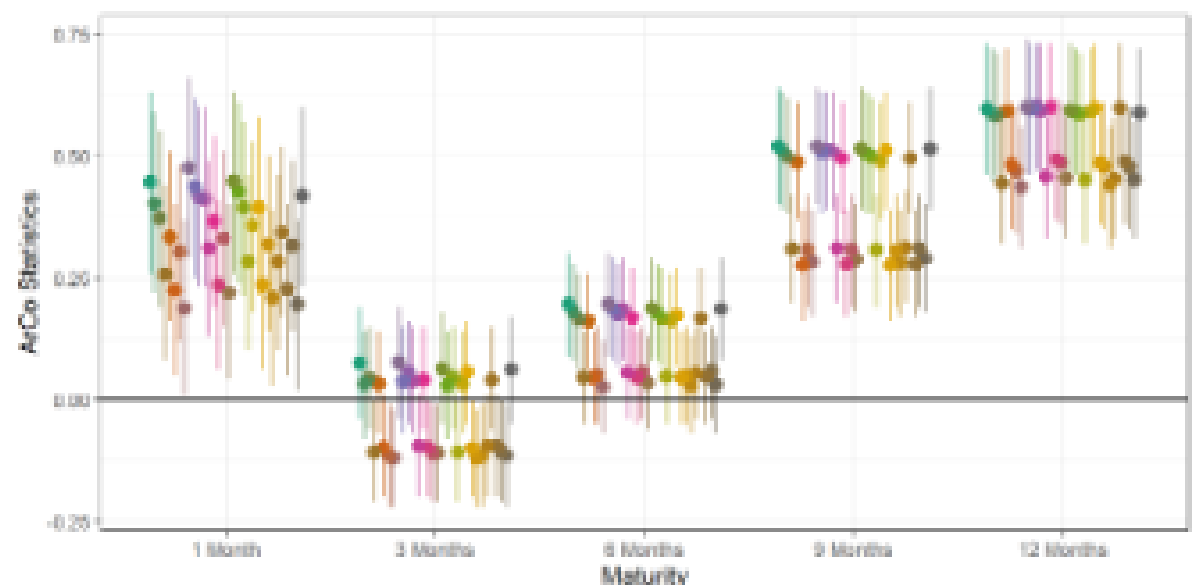

(c) CIP - Sample 9

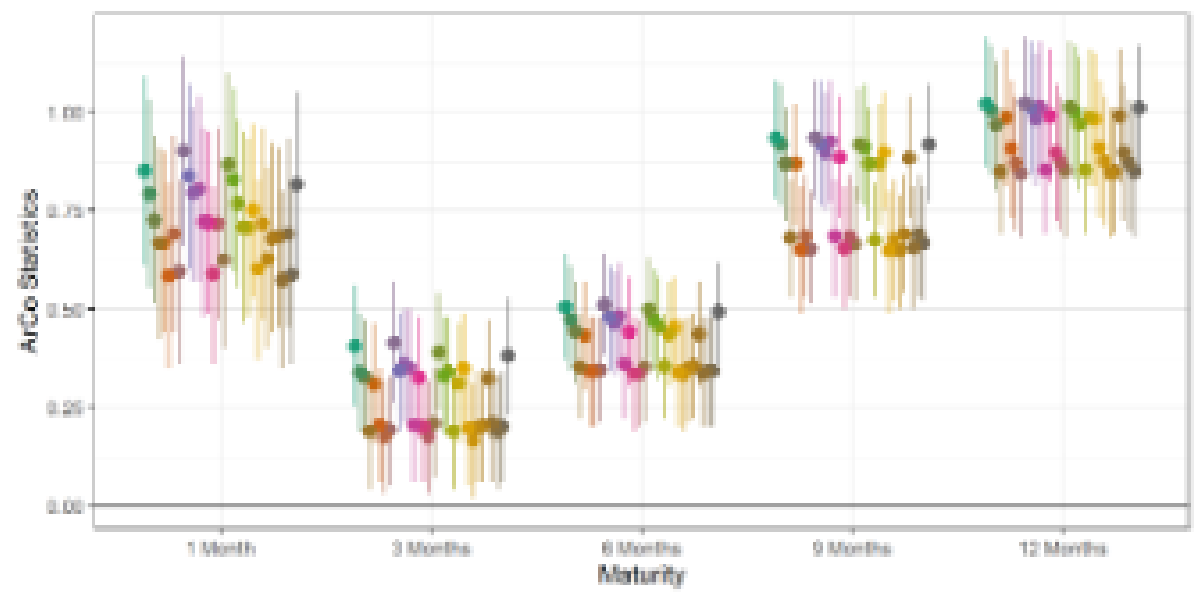

The colors represent an ArCo specification, as exposed in Table B.1. Each graphic represent a specific Sample division, as shown in Figure 3.1. The points represent the ArCo statistic, and the bars represent the 95\% confidence interval. Looking at the Forward Premium models, a negative statistic imply that the observed FP is lower then the estimated counterfactual, which in turn implies in a lower CIP deviation in the absence of intervention. 
Figure B.3: Results - Weekly ArCo - Pre 1

(a) CIP - Sample 2

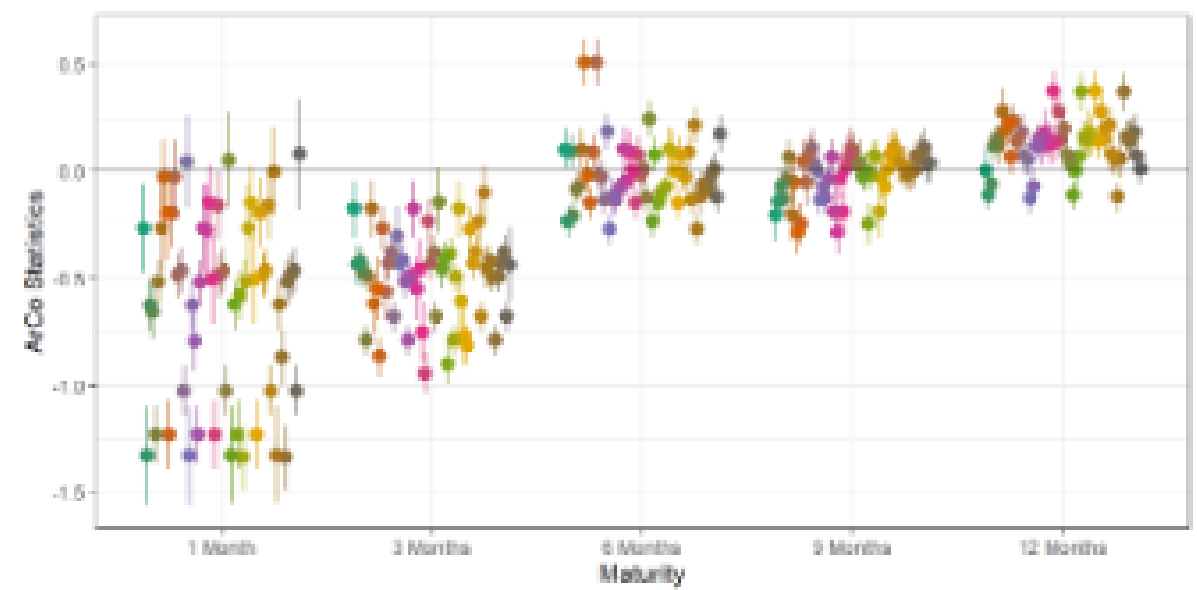

(c) CIP - Sample 4

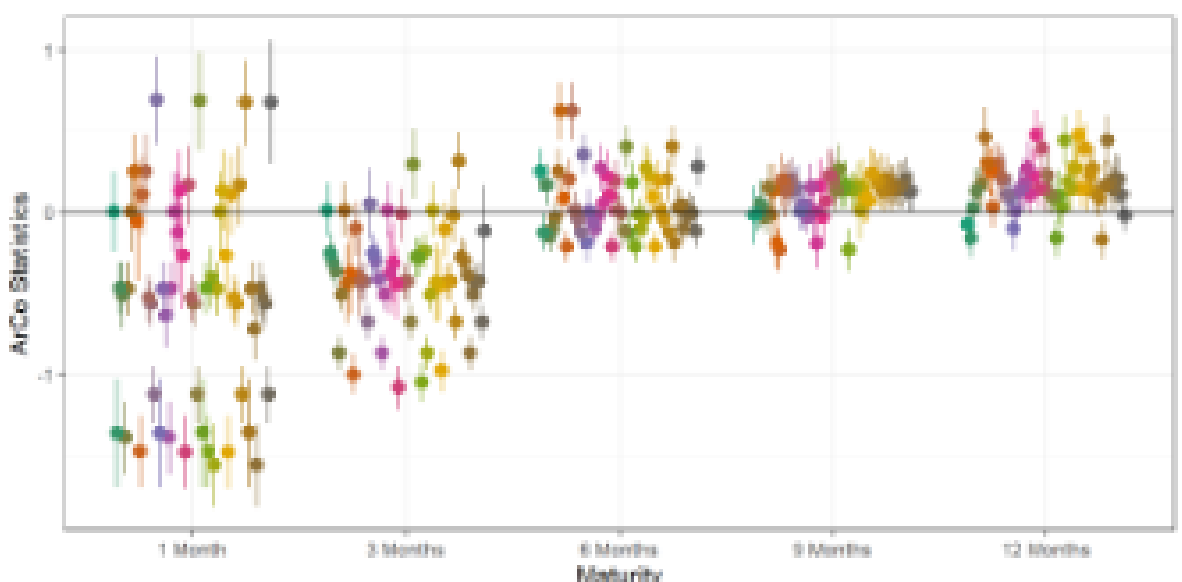

(b) CIP - Sample 3

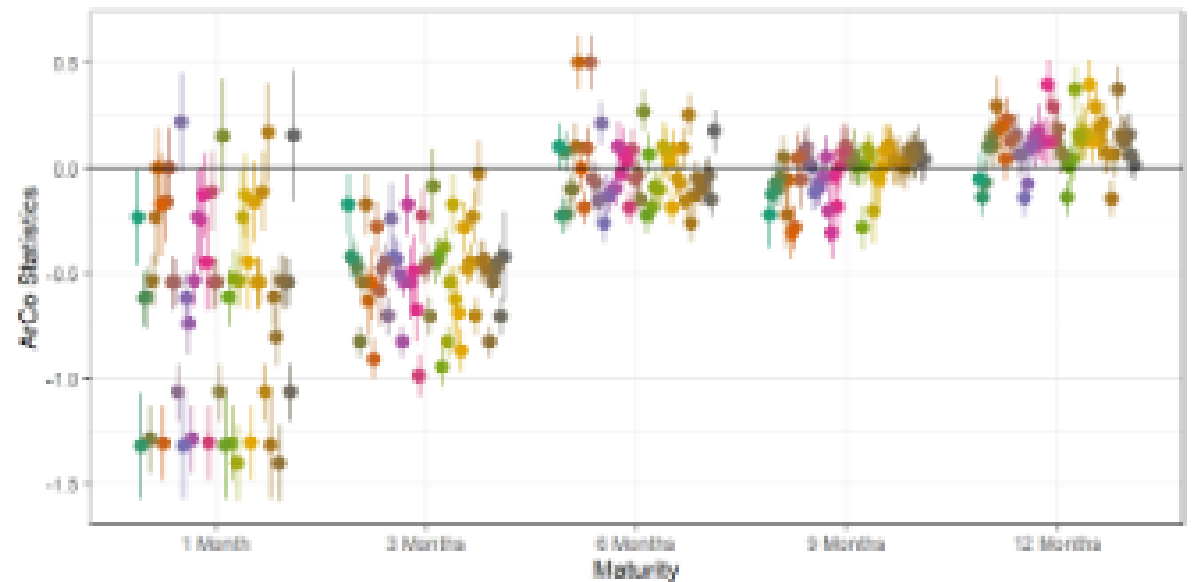

(d) CIP - Sample 5

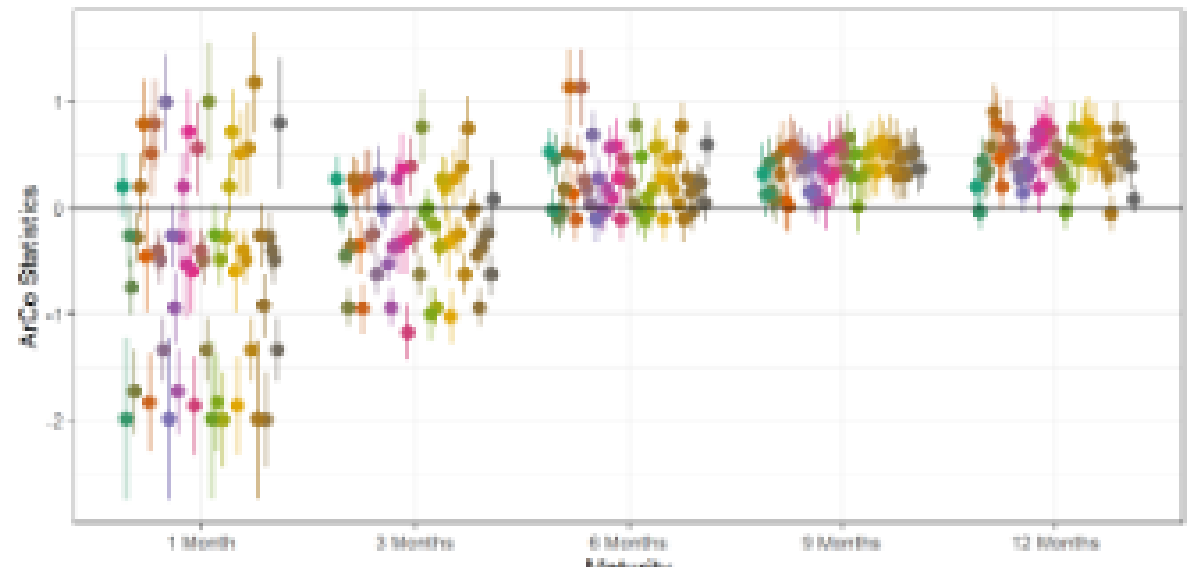

The colors represent an ArCo specification, as exposed in Table B.1. Each graphic represent a specific Sample division, as shown in Figure 3.1. The points represent the ArCo statistic, and the bars represent the $95 \%$ confidence interval. Looking at the Forward Premium models, a negative statistic imply that the observed FP is lower then the estimated counterfactual, which in turn implies in a lower CIP deviation in the absence of intervention. 
Figure B.4: Results - Weekly ArCo - Pre 2

(a) CIP - Sample 7

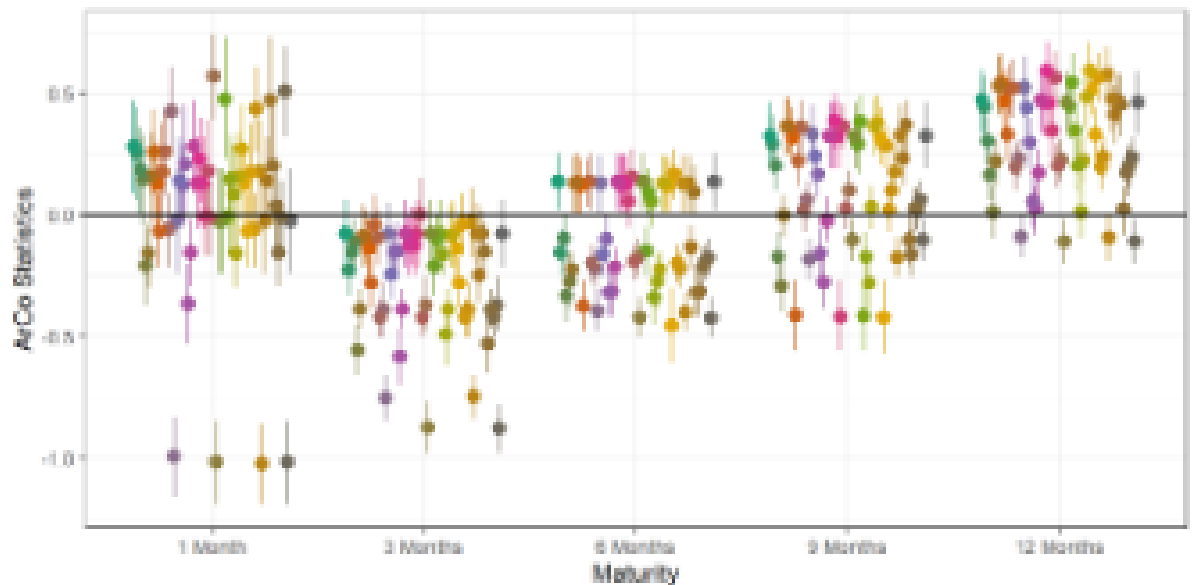

(b) CIP - Sample 8

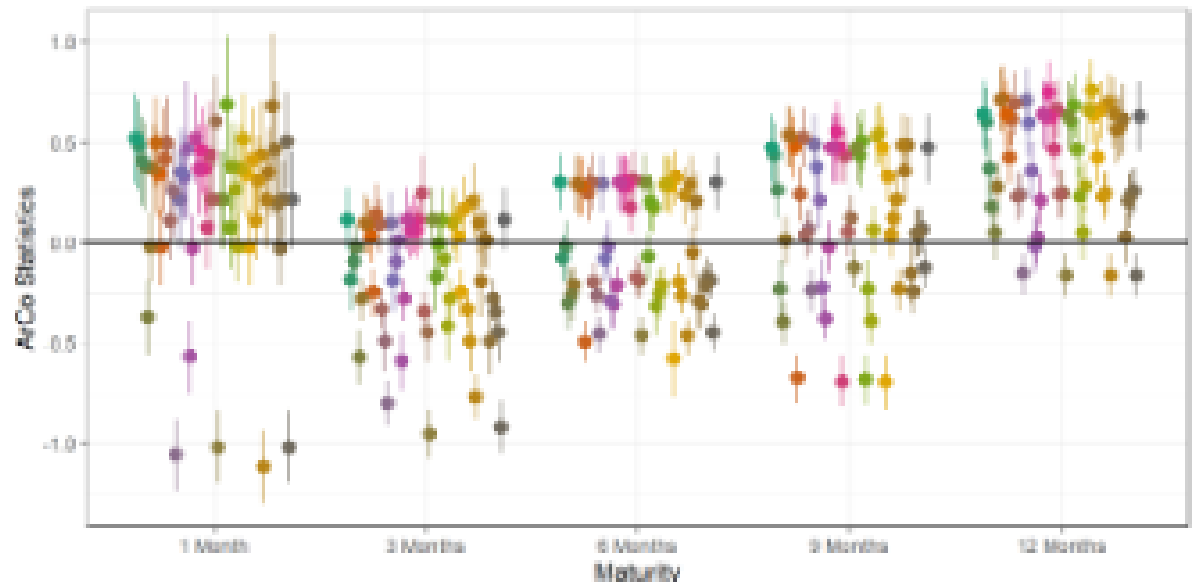

c) CIP - Sample 9

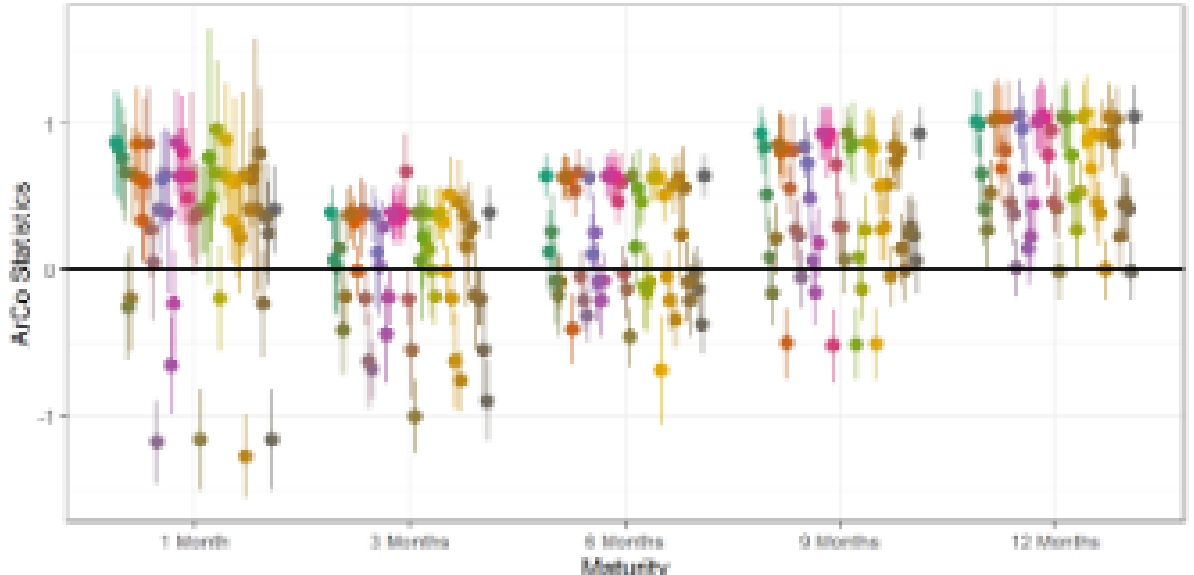

The colors represent an ArCo specification, as exposed in Table B.1. Each graphic represent a specific Sample division, as shown in Figure 3.1. The points represent the ArCo statistic, and the bars represent the 95\% confidence interval. Looking at the Forward Premium models, a negative statistic imply that the observed FP is lower then the estimated counterfactual, which in turn implies in a lower CIP deviation in the absence of intervention. 
Figure B.5: Results - Adjusted R-Squared

(a) Samples 1-5

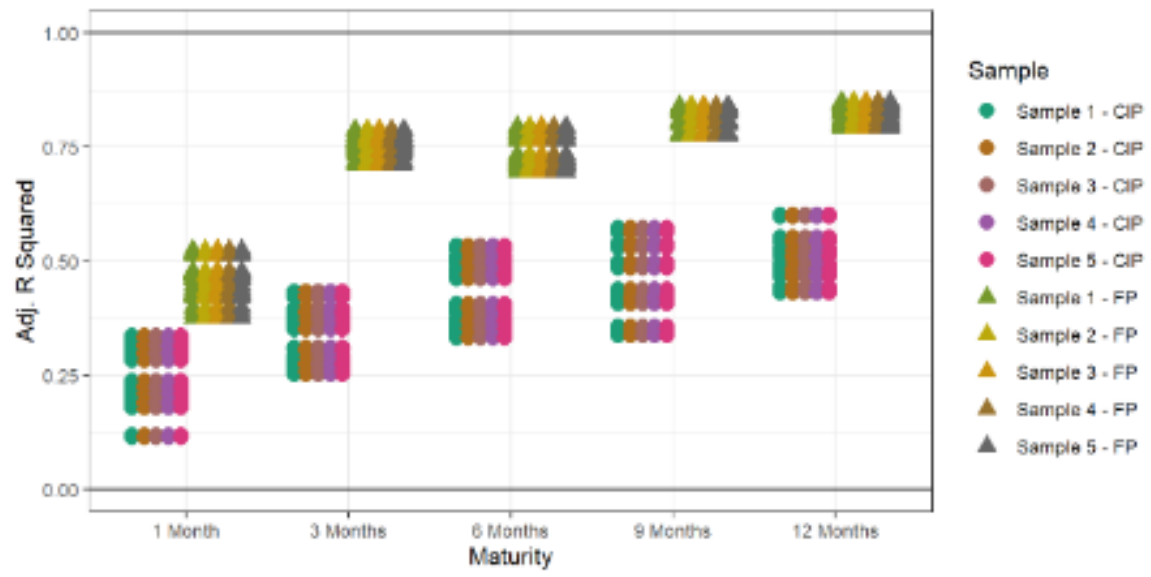

(b) Samples 6-9

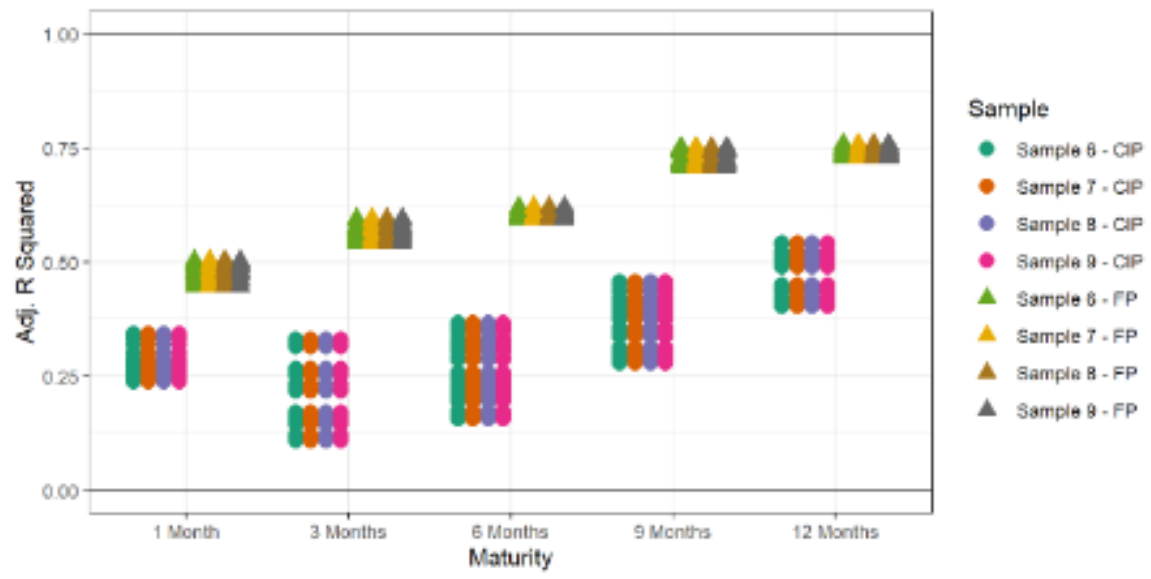

The colors represent the Samples correspond to the divisions, as shown in Figure 3.1. Sample 1 to 5 correspond to the period where BCB intervened in a discretionary way, and Sample 6 to 9 , the period after the program was announced. Each point represents the adjusted RSquared of specific specification, for the pre-treatment period, where the ArCo parameters were estimated. CIP and FP correspond to the specifications were the CIP were estimated directly or split between forward premium and interest rate differential 
Figure B.6: Swap Interventions Effect on CIP Deviations

(a) Swap - 3 Months

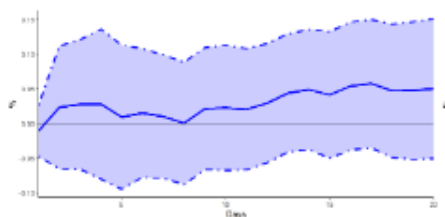

(d) Reverse Swap - 3 Mon.

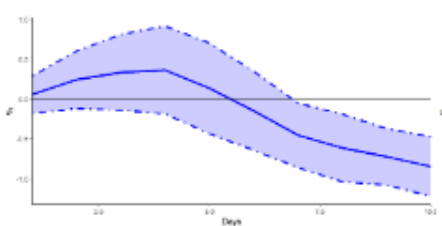

(b) Swap - 6 Months

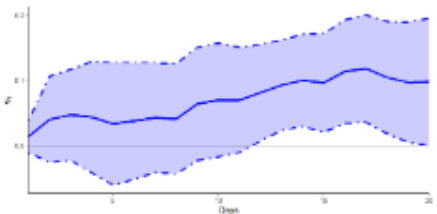

(e) Reverse Swap - 6 Mon.

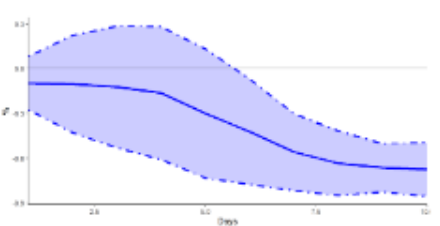

(c) Swap - 9 Months

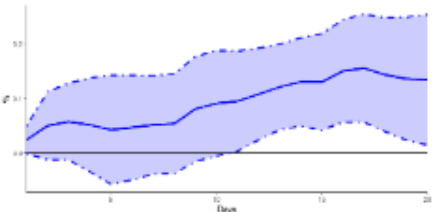

(f) Reverse Swap - 9 Mon.

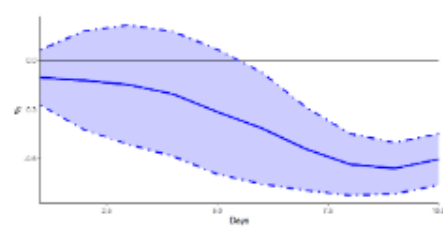

The regressions follow Equation 2-9. The CIP deviations are controlled by the log difference of 5-year Brazilian CDS, VIX and for the spread of bid-and-ask USDBRL in the spot market. We use 5 days lag in both endogenous and exogenous variables. The light blue line represents the $95 \%$ CI, calculated using Newey and West (1987).

Figure B.7: Swap Interventions Effect on CIP Deviations - Covid-19

(a) Swap - 3 Months

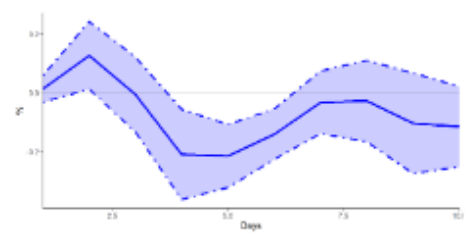

(b) Swap - 6 Months

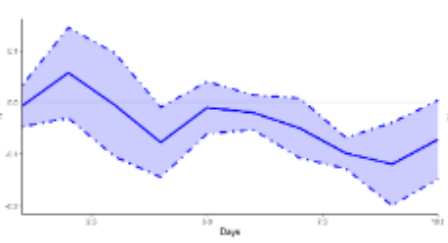

(c) Swap - 9 Months

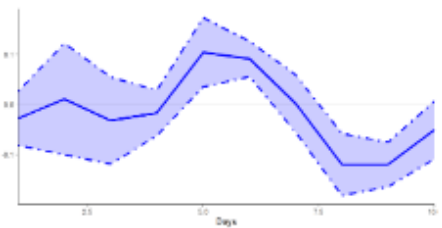

The regressions follow Equation 2-9. The CIP deviations are controlled by the log difference of 5-year Brazilian CDS, VIX and for the spread of bid-and-ask USDBRL in the spot market. We use 5 days lag in both endogenous and exogenous variables. The light blue line represents the $95 \%$ CI, calculated using Newey and West (1987). 
Figure B.8: Spot Interventions Effect on CIP Deviations

(a) Spot Purchase - 3 Mon.(b) Spot Purchase - 6 Mon.(c) Spot Purchase - 9 Mon.

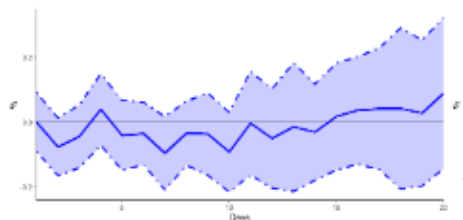

(d) Spot Sale - 3 Months

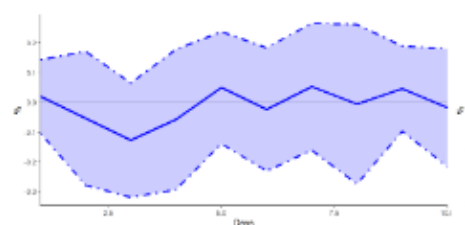

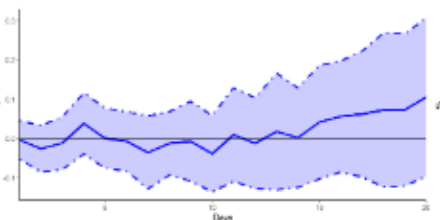

(e) Spot Sale - 6 Months

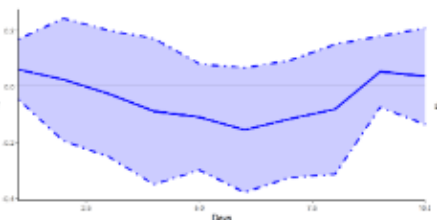

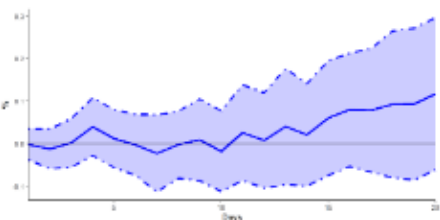

(f) Spot Sale - 9 Months

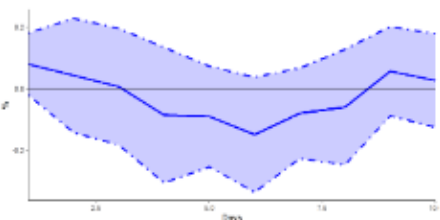

The regressions follow Equation 2-9. The CIP deviations are controlled by the log difference of 5-year Brazilian CDS, VIX and for the spread of bid-and-ask USDBRL in the spot market. We use 5 days lag in both endogenous and exogenous variables. The light blue line represents the $95 \%$ CI, calculated using Newey and West (1987).

Figure B.9: Reverse Swap Effect on CIP Deviations - 2H2019

(a) Reverse Swap - 3 Mon. (b) Reverse Swap - 6 Mon. (c) Reverse Swap - 9 Mon.
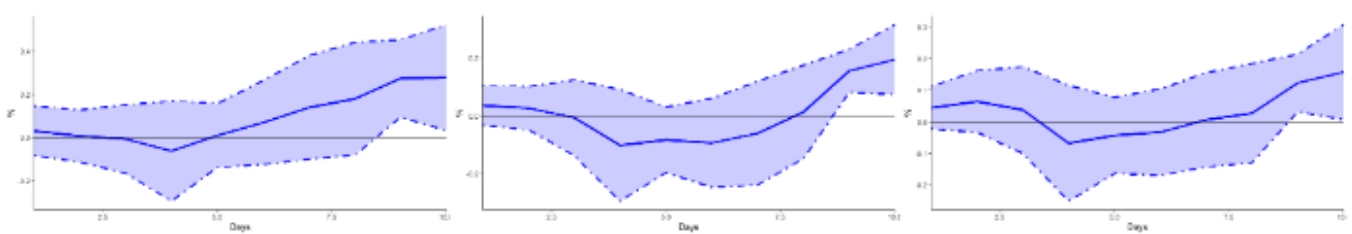

The regressions follow Equation 2-9. The CIP deviations are controlled by the log difference of 5-year Brazilian CDS, VIX and for the spread of bid-and-ask USDBRL in the spot market. We use 5 days lag in both endogenous and exogenous variables. The light blue line represents the $95 \%$ CI, calculated using Newey and West (1987). 
Figure B.10: Repo Interventions Effect on CIP Deviations

(a) Repo Purchase - 3 Mon.(b) Repo Purchase - 6 Mon.(c) Repo Purchase - 9 Mon.

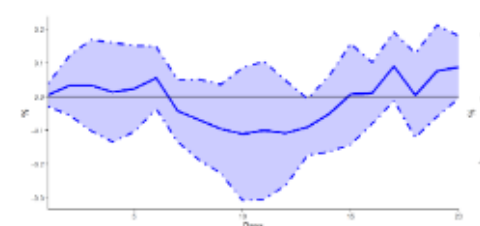

(d) Repo Sale - 3 Months

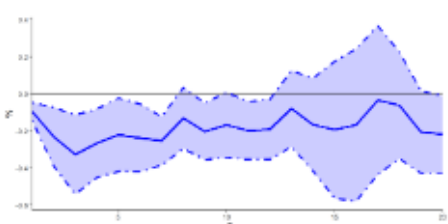

The regressions follow Equation 2-9. The CIP deviations are controlled by the log difference of 5-year Brazilian CDS, VIX and for the spread of bid-and-ask USDBRL in the spot market. We use 5 days lag in both endogenous and exogenous variables. The light blue line represents the $95 \%$ CI, calculated using Newey and West (1987). 